\title{
Construção e aplicação de um índice de vulnerabilidade humana à mudança do clima para o contexto brasileiro: a experiência do estado do Espírito Santo'
}

\section{Construction and application of a human vulnerability index for climate change in the Brazilian context: the experience of the state of Espírito Santo, Brazil}

\author{
Rhavena Barbosa dos Santos ${ }^{a}$ \\ (D) https://orcid.org/0000-0002-8999-2143 \\ E-mail: rhavena.santosळgmail.com \\ Júlia Alves Menezes ${ }^{a}$ \\ (D) http://orcid.org/0000-0002-1032-1997 \\ E-mail: menezes.jalvesळgmail.com

\section{Ulisses Confalonieria} \\ (D) https://orcid.org/0000-0002-8589-2866 \\ E-mail: uconfalonieriøgmail.com

\section{Ana Paula Madureirab} \\ (D) https://orcid.org/0000-0002-6614-7940 \\ E-mail: anapaulamadळhotmail.com

\section{Isabela de Brito Duvala} \\ (iD) https://orcid.org/0000-0002-5778-7532 \\ E-mail: isabelafbrito®gmail.com

\section{Poliana Pedro Garciac} \\ (iD) https://orcid.org/0000-0001-8708-6342 \\ E-mail: poliana.spedroœgmail.com

\section{Carina Margonaria} \\ (D) https://orcid.org/0000-0003-4251-1004 \\ E-mail: margonariळcpqrr.fiocruz.br
}

'Fundação Oswaldo Cruz. Instituto René Rachou. Belo Horizonte, MG, Brasil.

bUniversidade Federal de São João del-Rei. São João del-Rei, MG, Brasil.

'Universidade Federal de Minas Gerais. Belo Horizonte, MG, Brasil.

\section{Correspondência}

Rhavena Barbosa dos Santos

Instituto René Rachou. Av. Augusto de Lima, I.715, anexo, sala 21. Belo Horizonte, MG, Brasil. CEP 30190-009.

\section{Resumo}

A mudança do clima representa séria ameaça para a população humana, causando impactos em diferentes setores. Conhecer os fatores que elevam a vulnerabilidade do ser humano à mudança do clima permite identificar pontos críticos e direcionar ações imediatas para reduzi-la. Assim, este estudo desenvolveu e aplicou um índice de vulnerabilidade à mudança do clima para as microrregiões do Espírito Santo, abarcando os elementos fundamentais da vulnerabilidade - exposição, sensibilidade e capacidade adaptativa. Anomalias climáticas de precipitação e temperatura também foram usadas para estimar as alterações para o futuro. A construção dos indicadores se baseou na atribuição de notas indicativas de vulnerabilidade para cada grupo de municípios (clustering), com posterior média aritmética e padronização dos valores para gerar índices variando entre o e 1. Verificou-se que a microrregião Noroeste apresenta vulnerabilidade extremamente elevada, em virtude de características, sociodemográficas, econômicas e ambientais. Todo o estado poderá ser afetado por alterações do clima futuro, principalmente pelo aumento de temperaturas médias. 0 norte do estado poderá ter aumento no número de dias secos consecutivos. Espera-se que esses resultados contribuam para orientar ações de adaptação à mudança do clima e aumentar a 
resiliência do território a partir da identificação das vulnerabilidades existentes.

Palavras-chave: Mudança Climática; Estudo sobre Vulnerabilidade; Saúde Pública; Índice.

\section{Abstract}

Climate change poses a serious threat to the human population, causing impacts in different sectors. Understanding the factors that may increase human's vulnerability to climate change allows to identify critical points and to direct immediate actions to reduce vulnerability. Thus, this study developed and applied an index of vulnerability to climate change for the microregions of the state of Espírito Santo, Brazil, encompassing the key elements of vulnerability - Exposure, Sensitivity and Adaptive Capacity. Climatic anomalies of precipitation and temperature were also used for estimate future climate changes. Construction of the indicators was based on the assignment of scores indicating levels of vulnerability for each group of municipalities (clustering); subsequent arithmetic mean and standardization of the values were applied to generate indices from o and 1. The Northwestern microregion presented high vulnerability due to its sociodemographic, economic and environmental characteristics. In addition, the entire state may be affected by changes in future climate, mainly by the increase of average temperatures. The Northern region may have a considerable increase in the number of consecutive dry days. These results are expected to contribute to guide actions of adaptation to the climate change and to increase the resilience of the territory from the identification of existing vulnerabilities.

Keywords: Climate Change; Vulnerability Study; Public Health; Index.

\section{Introdução}

A mudança do clima, seja por causas naturais ou antrópicas, representa séria ameaça para a população humana, pois a alteração do padrão observado de temperatura e precipitação apresenta impactos, tanto diretos (secas, inundações e enxurradas) quanto indiretos (migração de pessoas e favorecimento da proliferação de doenças de veiculação hídrica e transmitidas por vetores). Essas alterações vêm sendo observadas em diferentes regiões brasileiras de forma não uniforme - são esperados redução da precipitação e aumento de temperatura na região Norte, enquanto na Sul espera-se aumento da precipitação (Brasil, 2016; Confalonieri, 2003; De Sherbinin et al., 2011; Filho et al., 2014).

Diante da relevância desses impactos, diferentes estudos no contexto da mudança do clima vem sendo desenvolvidos, seja abordando aspectos físicos (projeções de temperatura e precipitação oriundas de modelos climáticos globais), seja abordando a vulnerabilidade das populações e territórios (Cutter; Finch, 2008; Filho et al., 2014; Lee et al., 2015; Obermaier; Rosa, 2013). No que se refere à vulnerabilidade, vários tem sido os autores dedicados a compreender como a conjugação de fatores biofísicos, sociais, geográficos e econômicos pode contribuir para moldar os riscos e susceptibilidades das populações às alterações do clima, havendo uma gama de abordagens possíveis - social, risco-perigo, socioecológicas (Adger, 2006; Confalonieri; Barata; Marinho, 2015; Cutter; Finch, 2008; Füssel, 2007).

Para o Painel Intergovernamental sobre Mudança do Clima (IPCC), a vulnerabilidade é compreendida como a propensão de uma determinada população/ localidade a ser adversamente afetada por alterações do clima em função de três elementos fundamentais: sensibilidade, capacidade adaptativa e exposição (IPCC, 2007). A intrínseca relação entre esses três elementos pode ser expressa por:

$$
V=f(\varepsilon, S, C A)
$$

No qual a sensibilidade (S) está relacionada à maneira como um sistema pode ser afetado, de forma adversa ou não, a capacidade adaptativa (CA) está 
ligada à habilidade em diminuir ou evitar danos por meio da exploração de oportunidade benéficas existentes nos sistemas, e a exposição (E) é traduzida pela presença de pessoas, sistemas e suas relações, que podem ser adversamente afetados pela mudança do clima (IPCC, 2007; Obermaier; Rosa, 2013).

Diante da complexidade e variedade de informações existentes na temática da vulnerabilidade, os indicadores e índices tem sido um método largamente utilizado devido a sua capacidade de sistematizar a coleta de informações e facilitar a visualização de fenômenos complexos. (Barata et al., 2011; Brasil, 2016; Confalonieri; Barata; Marinho, 2015; Confalonieri, Quintão; Brito, 2016; Menezes et al., 2018; Quintão et al., 2017).

Os estados de Minas Gerais, Rio de Janeiro, Bahia e Amazonas, por exemplo, já conduziram estudos de vulnerabilidade pela utilização de índices específicos, que permitiram, além da compreensão dos fatores que tornam as populações de seus territórios susceptíveis ao clima, o mapeamento dessa vulnerabilidade no âmbito municipal (Barata et al., 2011; Menezes et al., 2018; Quintão et al., 2017).

A relevância desses estudos em âmbito nacional reside não apenas na capacidade de produzir informações concretas sobre um assunto cientificamente novo, mas também na competência de identificar os fatores que exigem ações imediatas para reduzir a vulnerabilidade de populações e territórios, sendo uma ferramenta útil para os tomadores de decisão. Entretanto, para a região Sudeste, o estado do Espírito Santo (ES) ainda não apresenta estudos nessa temática que possam contribuir para a resiliência do território e orientar ações de adaptação ao clima. Assim, este trabalho tem o intuito de desenvolver e aplicar um índice para as microrregiões do ES que abarcasse a realidade local a partir das três dimensões básicas da vulnerabilidade - exposição, sensibilidade e capacidade adaptativa.

\section{Modelo conceitual}

O índice de vulnerabilidade microrregional à mudança do clima (IVM) aplicado nesta pesquisa foi baseado em estudos anteriores realizados em outras localidades (Barata et al., 2011; Confalonieri; Barata; Marinho, 2015; Confalonieri; Quintão; Brito, 2016; Menezes et al., 2018; Quintão et al., 2017). É constituído por três subíndices que correspondem aos elementos fundamentais da vulnerabilidade: exposição, sensibilidade e capacidade adaptativa. Juntos, esses componentes originam o índice de vulnerabilidade (IV), responsável por retratar as condições de vulnerabilidade de cada município.

O subíndice de exposição (IE) abarcou informações sobre pessoas vivendo em zonas de baixa elevação costeira (a 10 metros de altitude e $50 \mathrm{~km}$ da linha costeira), cobertura vegetal nativa, número de ocorrência de desastres naturais e óbitos atribuídos a esses eventos e percentual de população vivendo em áreas de risco para movimento de massa e eventos hidrológicos.

O subíndice de sensibilidade (IS) retratou características sociodemográficas, de pobreza e de ocorrência de doenças (dengue, leptospirose e leishmaniose tegumentar americana), que podem tornar a população mais susceptível aos impactos da mudança do clima. Já o subíndice de capacidade adaptativa (ICA) procurou avaliar a presença de estruturas e instituições que favorecem a ação da população perante situações adversas do clima, incluindo a presença de entidades de segurança (como Defesa Civil, Corpo de Bombeiros e Guarda Municipal), unidades de saúde e conselhos e consórcios municipais e intermunicipais.

Para representar a exposição futura à mudança do clima, são associadas ao IV variáveis climáticas que consideram os cenários futuros - representative concentration pathways $4.5 \mathrm{~W} / \mathrm{m}^{2}$ e $8.5 \mathrm{~W} / \mathrm{m}^{2}$ (RCP 4.5 e 8.5). Esses cenários pertencem à terceira geração de cenários produzidos pelo IPCC e representam diferentes contextos de concentração de gases do efeito estufa (GEE) até o ano de 2100. Para estimar a concentração de GEE até o final do século, eles se baseiam em suposições sobre atividade econômica, fontes de energia, crescimento da população e outros fatores socioeconômicos mundiais. Ao serem agregados ao modelo regional Eta-HadGEM2-ES, eles permitem produzir simulações do clima presente (1961-1990) e do clima futuro (2041-2070) para a América do Sul em diferentes contextos de emissão (Chou et al., 2014). Neste estudo, optou-se por utilizar 
as saídas do modelo Eta-HadGEM2-ES RCP 4.5 e 8.5 pois estes consideram, respectivamente, uma estabilização do GEE até o final do século (um cenário mais otimista) e um rápido incremento das emissões até 2100 (um cenário pessimista).

O fundamento teórico para a construção dos subíndices se baseou na literatura científica nacional e internacional voltada para a avaliação da vulnerabilidade socioambiental e de saúde, bem como seus impactos (Barata et al., 2011;
Confalonieri; Quintão; Brito, 2016; Füssel, 2007; Menezes et al., 2018; Quintão et al., 2017; Rolim, 2005). Os dados utilizados satisfizeram dois critérios: serem de livre acesso e sistematicamente atualizados, uma vez que o foco do IVM é permitir o monitoramento da vulnerabilidade das microrregiões do ES ao longo do tempo.

A Figura 1 contém a estrutura resumida do índice, enquanto o Quadro 1 evidencia todas as variáveis utilizadas.

Figura I - Estrutura do índice de vulnerabilidade microrregional à mudança do clima para o estado do Espírito Santo

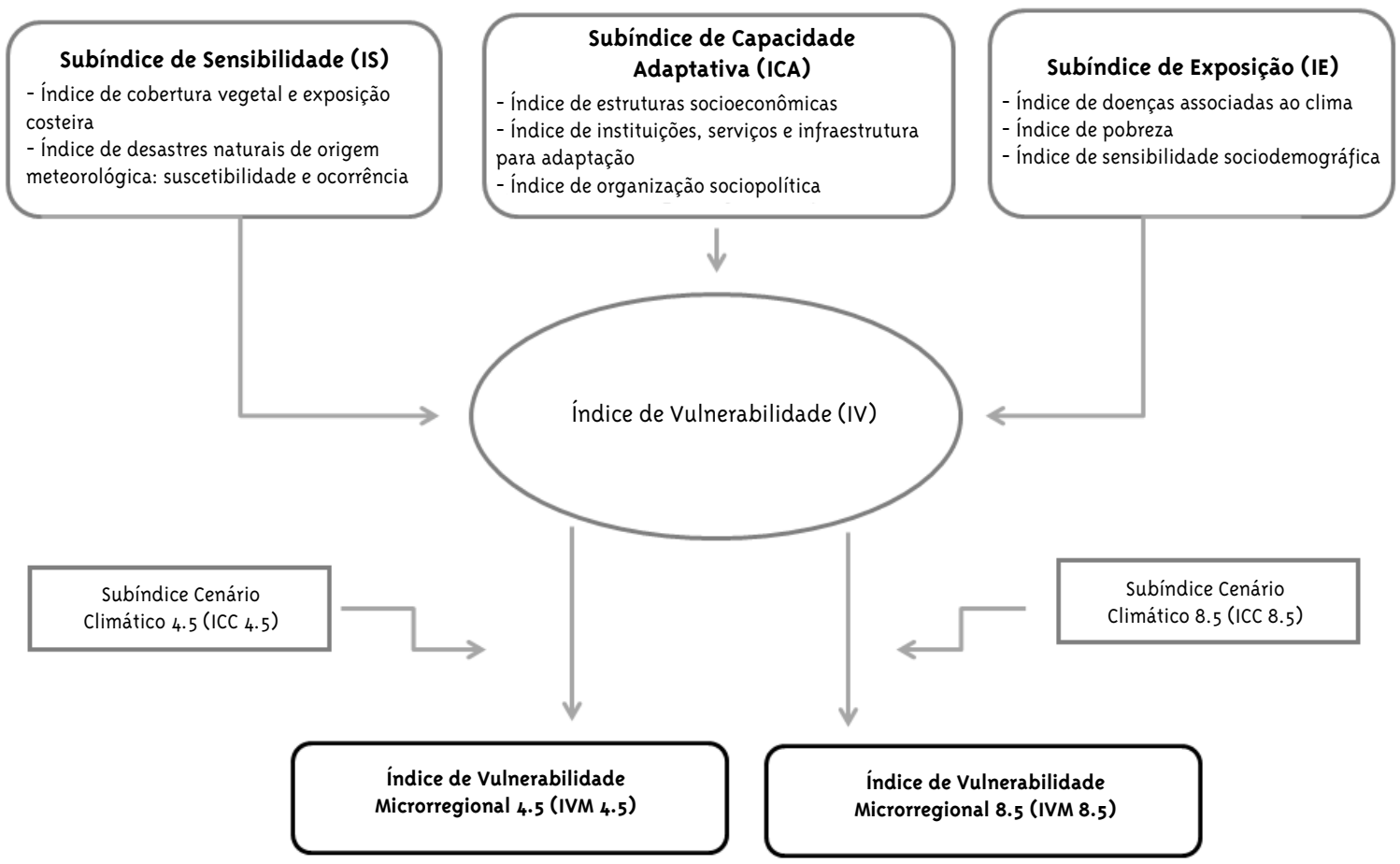




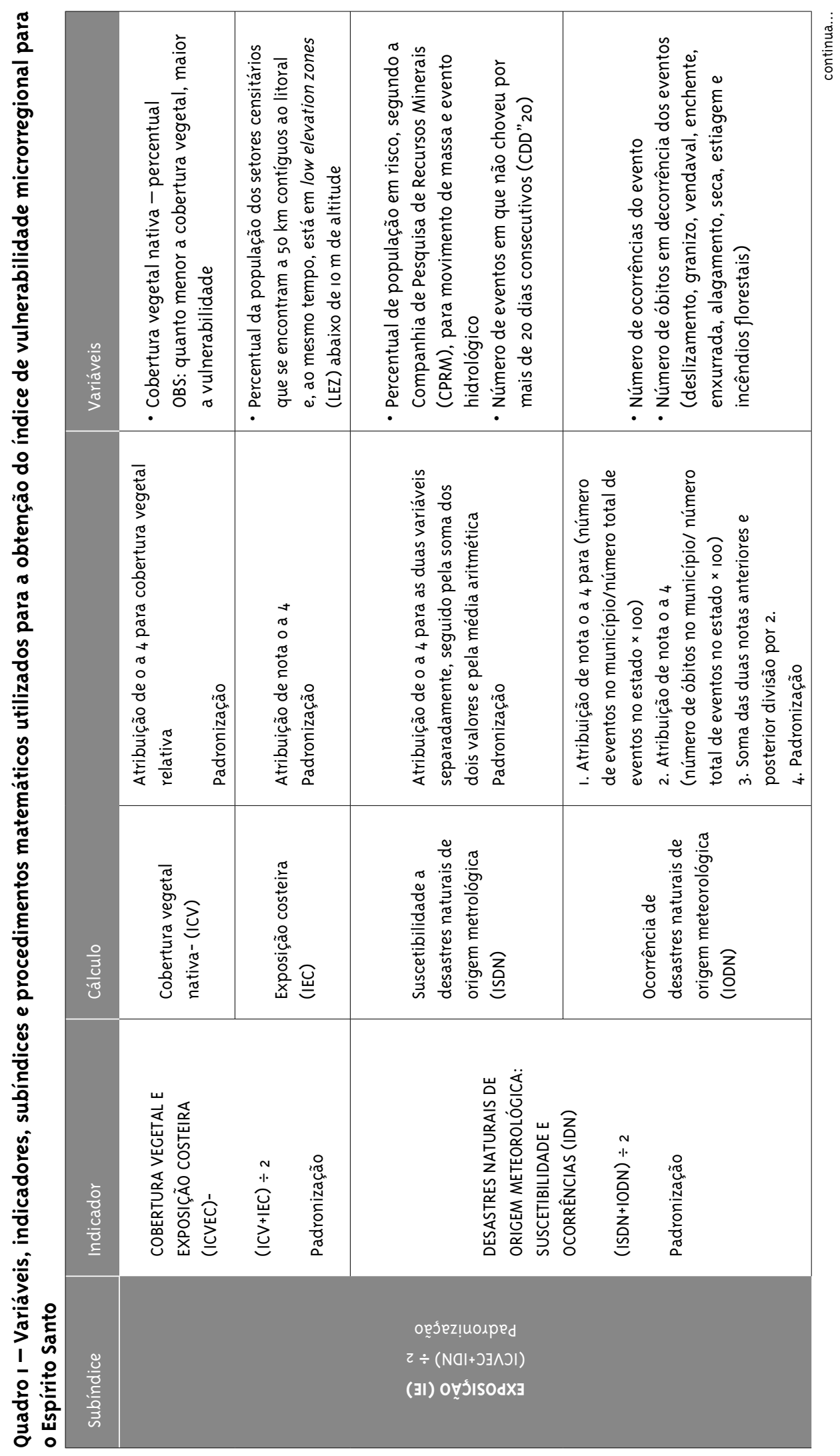




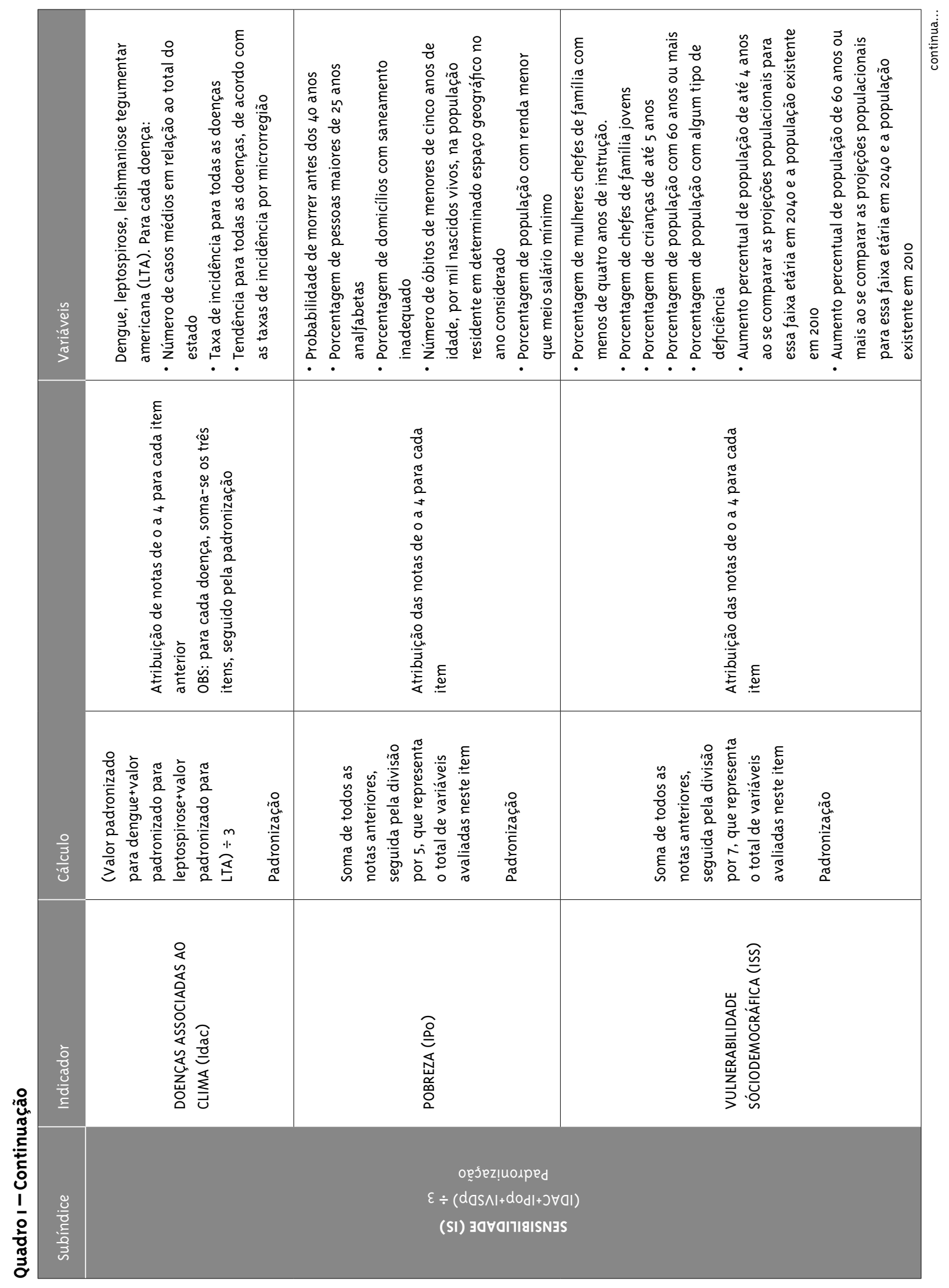




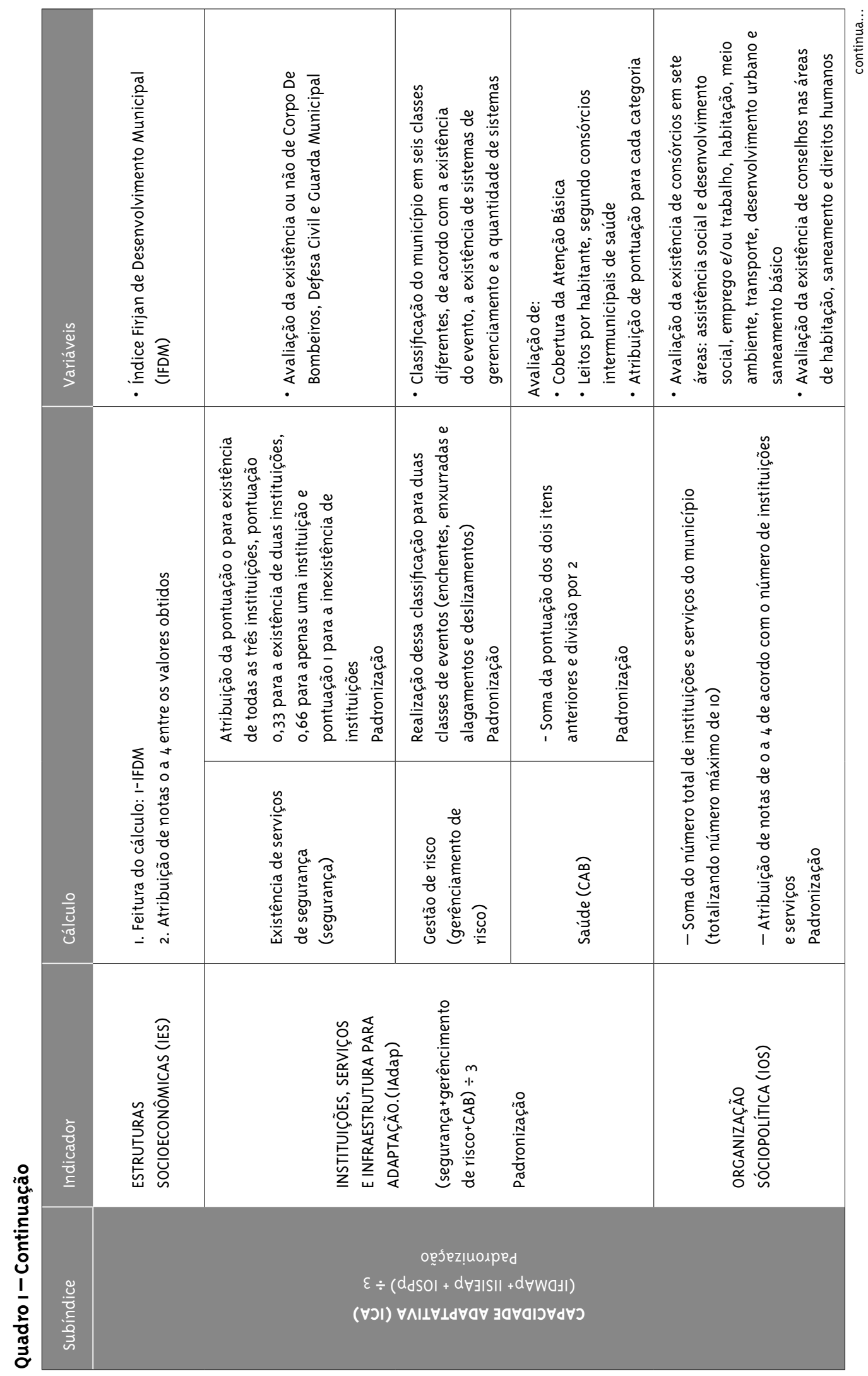




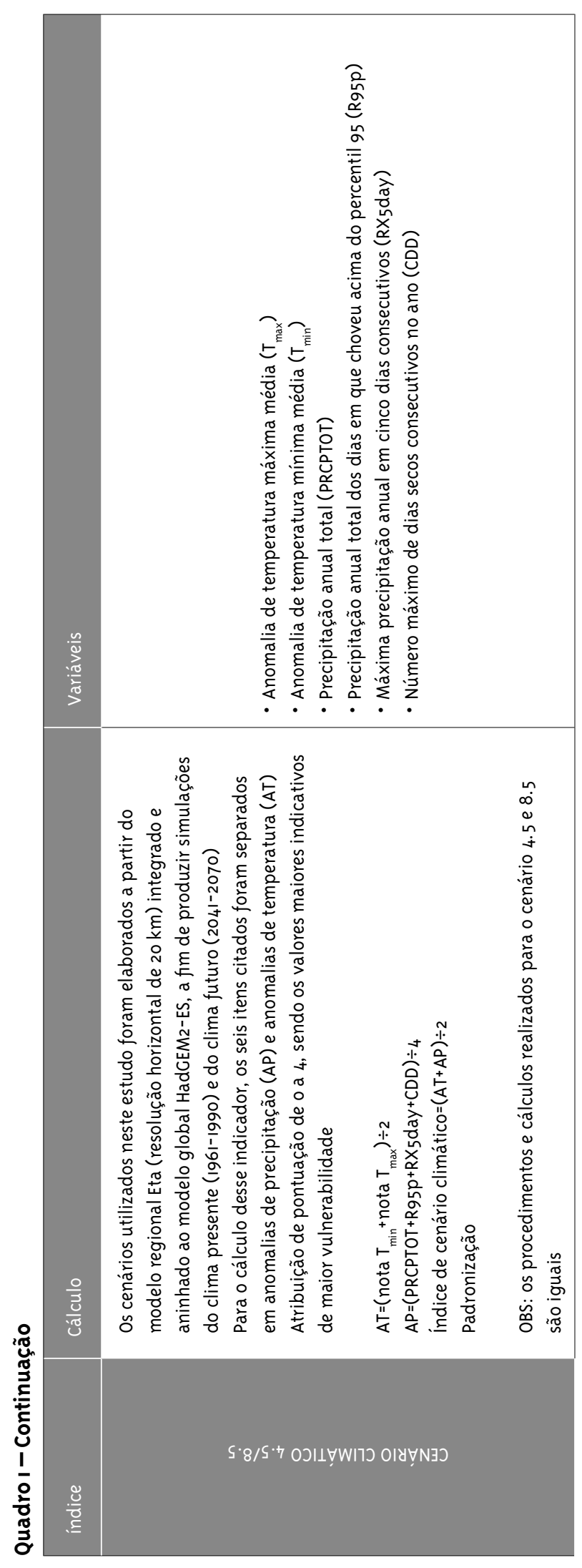

Saúde Soc. São Paulo, v.28, n.l, p.299-321, 2019306 


\section{Material e métodos}

\section{Área de estudo}

O estado do ES, é composto por 78 municípios e possui extensão de $46.096,925 \mathrm{~km}^{2}$. Localizado no Sudeste do Brasil, em região intertropical, faz divisa ao norte com o estado da Bahia, ao sul com o Rio de Janeiro e ao oeste com Minas Gerais, sendo banhado ao leste pelo Oceano Atlântico. Segundo a Lei 9.768, de 20 de dezembro de 2011, está dividido em 10 microrregiões de planejamento (Espírito Santo, 2011) (Figura 2).

O estado, que originalmente possuía $100 \%$ de seu território inserido no bioma Mata Atlântica, apresentou em 2016 um remanescente florestal de apenas $10,5 \%$ e crescimento de $106 \%$ do desmatamento ao compararmos os períodos de 2014/2015 e 2015/2016 (SOS Mata Atlântica; Inpe, 2018).

Nos últimos cinco anos, o ES tem sofrido com eventos referentes às chuvas concentradas e longos períodos de estiagem. Entre os anos de 1991 e 2012, os desastres naturais afetaram quase cinco milhões de pessoas no estado (Ceped, 2013).

Os impactos das alterações do clima têm influenciado também a economia do estado, conforme evidenciado pelo panorama econômico estadual divulgado para o último trimestre de 2016; foi evidenciada queda em nove das onze principais culturas do estado, sendo esse impacto atribuído à crise hídrica vivenciada em 2016 (Espírito Santo, 2017).

\section{Figura 2 - Localização geográfica e divisão microrregional do estado do Espírito Santo}
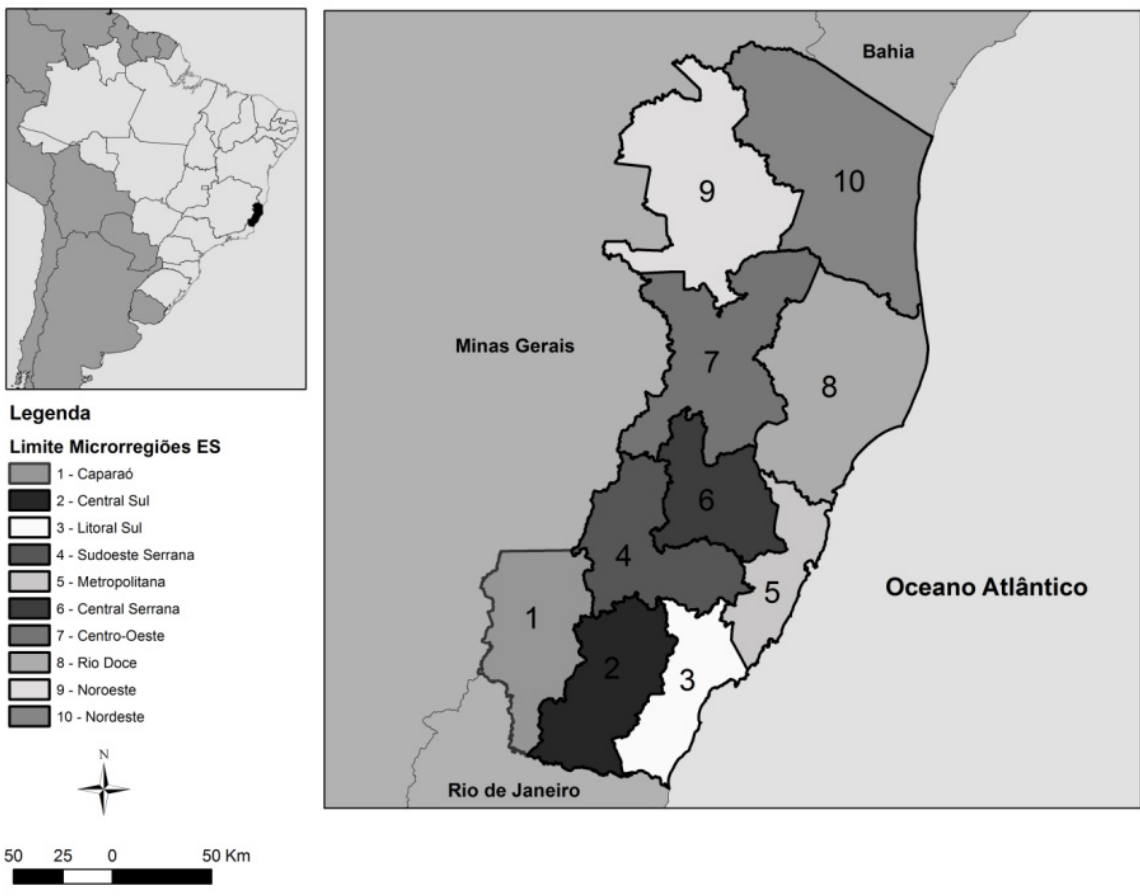

\section{Fonte de dados}

Os dados utilizados nesta pesquisa - referentes a exposição costeira, pobreza, organização sociopolítica, vulnerabilidade sociodemográfica e instituições, serviços e infraestrutura para adaptação - são provenientes do Instituto Brasileiro de Geografia e Estatística (IBGE). Para doenças e cobertura da atenção básica, foram usados dados do Departamento de Informática do Sistema Único de Saúde (Datasus). Informações sobre estruturas socioeconômicas foram 
provenientes do Índice Firjan de Desenvolvimento Municipal (IFDM), enquanto dados sobre desastres são oriundos da Companhia de Pesquisa de Recursos Minerais (CPRM) e do Atlas Brasileiro de Desastres Naturais, elaborado pela Universidade Federal de Santa Catarina (UFSC) em parceria com o Centro Universitário de Estudos e Pesquisas sobre Desastres (Ceped/PR) (Quadro 1).

As informações utilizadas foram coletadas a nível municipal para todo o estado do Espírito Santo - porém, para alguns indicadores, devido à ausência de informações atualizadas em escala municipal, os dados tiveram que ser produzidos durante a execução do projeto por meio da contratação de técnicos com experiência nas respectivas áreas. Esse foi o caso da cobertura vegetal nativa, das projeções climáticas utilizadas para construção dos índices de cenário climático e das projeções populacionais para 2040, os quais não estavam disponíveis de forma atualizada para todos os municípios do estado em sites de livre acesso.

\section{Cálculo do indice}

Os dados foram analisados no Microsoft Excel. Primeiramente, as informações municipais foram agrupadas em clusters por meio do agrupamento de valores (clustering por K-means), de forma que fossem criados grupos de municípios para a atribuição de notas indicativas de vulnerabilidade. O sistema cria cinco grupos, que recebem notas de o a 4, nos quais o significa menor vulnerabilidade e 4 maior vulnerabilidade. A análise de cluster é um procedimento que permite a partição de um conjunto de dados em grupos, não havendo o estabelecimento prévio de valores para delimitar as classes, e sim uma busca por similaridades e heterogeneidades entre os dados que permitam classificá-los nos mencionados clusters (Doni, 2004). Há estabelecimento de pontos centrais (centroides) e os integrantes de cada grupo são identificados segundo a distância para estes pelo método dos mínimos quadrados. Esse procedimento é feito para cada variável.

Após a atribuição das notas, foi calculada a média aritmética desses valores de forma a construir os subíndices e índices. Por exemplo, cada município recebe uma nota para a cobertura vegetal e outra para a exposição costeira. A média aritmética desses valores é o que gera o índice de cobertura vegetal e exposição costeira para cada município. 0 resultado obtido passa então por uma padronização, a fim de que os valores estejam sempre entre o e 1. Em seguida, os municípios são agrupados por microrregião para se calcular a média aritmética e obter o resultado microrregional. Por exemplo, a microrregião Noroeste é composta por sete municípios, cada um deles possuindo um resultado para o IE; ao se calcular a média do IE entre esses municípios, é obtido o IE para a microrregião. Esse procedimento acontece em todos os índices e subíndices e os resultados passam por nova padronização. Todas as padronizações realizadas obedeceram à Equação 1.

Os subíndices IS, IE e ICA foram agrupados por meio deste procedimento matemático (Equação 2).

Dessa forma, para o cálculo do IV da microrregião Noroeste, por exemplo, foi realizada a média aritmética de seus valores referentes ao IE, IS e ICA. O valor obtido foi padronizado de acordo com a Equação 1, para que o IV variasse entre o e 1.

\section{Equação I - Equação para Padronização de subíndices e índices}

Índice ou indicador padronizado

(Valor observado para o município)-(menor nota entre os municípios do estado)

$=\overline{\text { (maior nota entre os municípios do estado)-(menor nota entre os municípios do estado) }}$

\section{Equação 2 - Composição do Índice de Vulnerabilidade}

$I V=$ Subíndice de exposição +Subíndice de sensibilidade+Subíndice de capacidade adaptativa/ 
Por fim, o IVM é formado a partir do IV e do ICC 4.5/8.5 (Equação 3) e também varia entre o e 1. Ao fim dos cálculos, cada microrregião apresentará dois valores de IVM, um considerando o cenário climático mais otimista (ICC 4.5), proveniente da união do IV com as variáveis climáticas que consideram o RCP 4.5, e outro considerando as variáveis climáticas para o cenário pessimista (ICC 8.5).

\section{Equação 3 - Composição do Índice de Vulnerabilidade Municipal 4.5 e 8.5}

$$
\begin{aligned}
& I V M 4.5=(I V+I C C 4.5) / 2 \\
& I V M 8.5=(I V+I C C 8.5) / 2
\end{aligned}
$$

Os valores dos índices foram categorizados da seguinte forma: o a o,33 - baixa vulnerabilidade; o,34 a o,66 - vulnerabilidade moderada; e o,67 a 1 - vulnerabilidade alta.

Destaca-se que o índice é comparativo, portanto, a pontuação zero não indica ausência de vulnerabilidade, ao passo que a pontuação 1 não significa vulnerabilidade completa e sim que, em relação às demais microrregiões do estado, determinada microrregião é mais ou menos vulnerável (Santos, 2016). Dessa forma, o IVM permite uma análise comparativa das microrregiões do ES, o que evidencia os hotspots de vulnerabilidade diante das futuras alterações do clima.

\section{Resultados}

A média do IV no estado do ES foi de o,37 (moderada). As microrregiões Caparaó (o,41), Litoral Sul $(0,43)$, Centro-Oeste $(0,71)$, Nordeste $(0,73)$ e Noroeste $(1,00)$ apresentaram vulnerabilidade moderada a elevada, com valor médio de IV superior ao estadual; destacam-se as duas últimas, por apresentarem os maiores IV do estado (Tabela 1). Esses resultados também podem ser verificados espacialmente na Figura 3, em que é mostrada a distribuição dos valores do IV para as microrregiões do estado do ES. As colorações mais escuras indicam maior vulnerabilidade, predominante ao norte do estado, com destaque para a microrregião Noroeste.

Entretanto, os índices que contribuíram para elevar a vulnerabilidade (IV) das microrregiões mais críticas - Nordeste e Noroeste - foram distintos (Tabela 1). No
Nordeste, observou-se que o alto valor do ICA foi um dos componentes relevantes para o elevado IV. Dentre as variáveis utilizadas para cálculo do ICA, ressalta-se o desempenho das microrregiões naquelas relacionadas às estruturas socioeconômicas, ou seja, aos baixos níveis de geração de emprego e renda, atendimento à saúde e qualidade da educação (Tabela 1).

\section{Tabela I - Subíndices $e$ índices de vulnerabilidade microrregional para o estado do Espírito Santo}

\begin{tabular}{lc|c|c|c|c|c}
\multicolumn{7}{c}{ Subindices e indices } \\
\hline & IE & IS & ICA & IV & $\begin{array}{c}\text { ICC } \\
8.5\end{array}$ & $\begin{array}{l}\text { IVM } \\
\text { IV }\end{array}$ \\
\hline Média estadual & 0,42 & 0,41 & 0,49 & 0,37 & 0,61 & 0,46 \\
\hline Microrregião & & & & & & \\
Rio Doce & 0,31 & 0,05 & 0,36 & 0,11 & 0,57 & 0,26 \\
Caparaó & 0,11 & 0,38 & 1,00 & 0,41 & 1,00 & 0,73 \\
Noroeste & 1,00 & 1,00 & 0,69 & 1,00 & 0,81 & 1,00 \\
Nordeste & 0,41 & 0,92 & 0,88 & 0,73 & 0,52 & 0,64 \\
Centro-Oeste & 0,73 & 0,69 & 0,66 & 0,71 & 0,98 & 0,92 \\
Sudoeste Serrana & 0,00 & 0,52 & 0,19 & 0,08 & 0,39 & 0,12 \\
Central Serrana & 0,33 & 0,06 & 0,57 & 0,22 & 0,74 & 0,43 \\
Litoral Sul & 0,79 & 0,23 & 0,36 & 0,43 & 0,00 & 0,12 \\
Metropolitana & 0,29 & 0,22 & 0,00 & 0,02 & 0,25 & 0,00 \\
Central Sul & 0,24 & 0,00 & 0,23 & 0,00 & 0,80 & 0,33 \\
\hline
\end{tabular}

Já na microrregião Noroeste, percebeu-se o IS e o IE $(1,00)$ mais elevados em relação ao ICA, apesar de todos os valores pertencerem à categoria de alta vulnerabilidade (Tabela 1). A elevada pobreza dos municípios foi fator importante nesse componente.

As análises dos ICC 4.5, assim como do ICC 8.5, apresentam padrões semelhantes de distribuição espacial para a mudança do clima ao Sul do estado. A grande diferença entre os mapas consiste principalmente na microrregião Noroeste (Figura 4). No ICC 4.5 esta microrregião não está entre as mais afetadas do estado pela mudança do clima; porém, ao se analisar o ICC 8.5, essa mesma microrregião figura estre as mais afetadas. De forma geral, para o ICC 8.5, todo o Norte do estado poderá ser extremamente afetado - essa região também é destacada pelo alto IV. Considerando que as mudanças climáticas representadas pelo ICC 8.5 podem intensificar quadros de alta vulnerabilidade diagnosticados pelo IV, os próximos resultados descreverão o ICC 8.5. 


\section{Figura 3 - Índice de vulnerabilidade (IV) por microrregião para o estado do Espírito Santo}

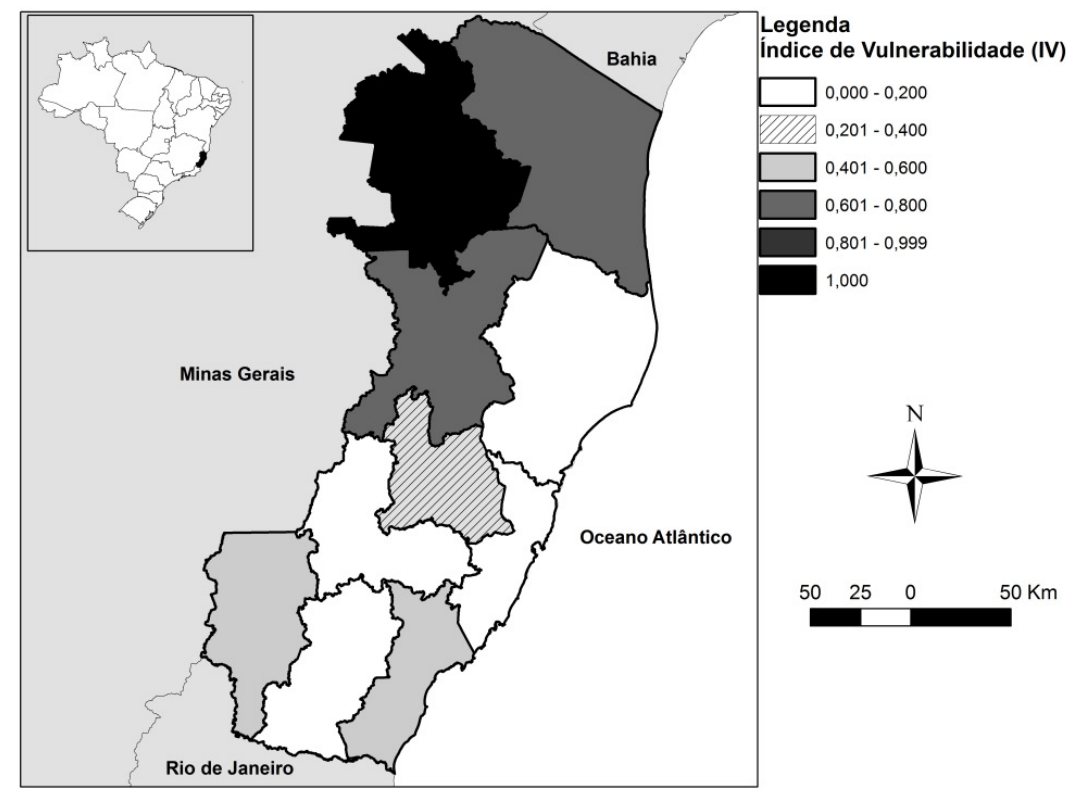

No ICC 8.5, percebeu-se que o componente de temperatura, em geral, apresentou maior valor em todo o estado quando comparado à precipitação. Há um padrão de alterações bem delimitado quanto às alterações de temperatura. No litoral do estado, observou-se valores menores de anomalias, que se elevaram estado adentro. Quanto aos resultados relacionados à precipitação, percebe-se que, em geral, os municípios ao norte poderão apresentar alterações pluviométricas mais severas que a região Sul. Vale destacar o aumento do número de dias secos consecutivos, que integra as anomalias de precipitação, pela grande área do estado afetada por essa alteração. Na microrregião Metropolitana, as alterações de precipitação foram mais relevantes que as de temperatura (Figura 4); essa microrregião, além de apresentar diminuição da precipitação media anual e aumento do número de dias secos consecutivos, também poderá ter aumento da ocorrência de chuvas concentradas, responsáveis por desastres de enxurrada, inundação e deslizamentos.

A microrregião Caparaó apresentou o maior valor ICC 8.5 (1,oo). Assim como na maioria do estado, a temperatura é o componente que mais influenciou o ICC 8.5 (Figura 4). Os possíveis aumentos de temperatura na região podem atingir até $2{ }^{\circ} \mathrm{C}$ na média anual de temperatura mínima e $4{ }^{\circ} \mathrm{C}$ na média de temperatura máxima.

O município do estado com maior valor de ICC 8.5 $(1,0)$ foi São José do Calçado, localizado na microrregião Caparaó. O segundo maior valor de ICC 8.5 foi o,83, considerado alto, verificado para 13 municípios: São Gabriel da Palha, São Domingos do Norte, Ibatiba, Rio Bananal, Apiacá, Vila Pavão, Vila Valério, Jerônimo Monteiro, São Roque do Canaã, Marilândia, Muniz Freire, Bom Jesus do Norte e Guaçuí (Tabela 2). 0 grande número de municípios com alto valor de ICC 8.5 traduz a elevada exposição futura a alterações do clima que pode ocorrer em boa parte do estado. 
Figura 4 - Índice de cenários climáticos RCP 4.5 e 8.5 por microrregião para o estado do Espírito Santo

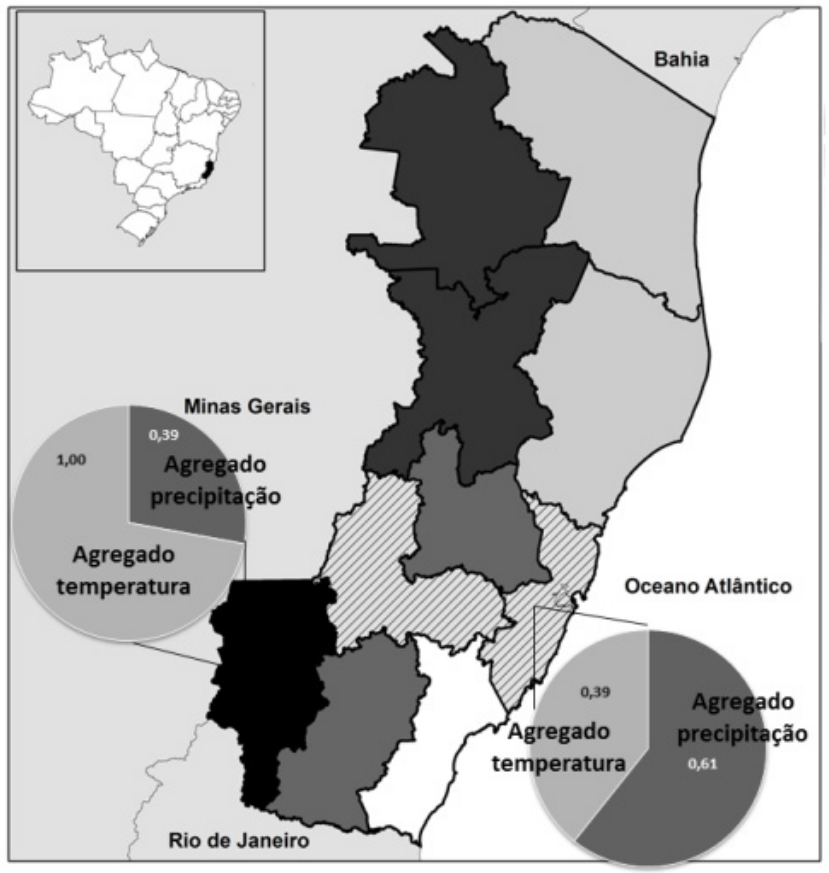

\section{Legenda}

Índice de Cenário Climático 8.5

(ICC 8.5)

\begin{tabular}{l}
\hline $0,000-0,200$ \\
$\square, 201-0,400$ \\
$\square 0,401-0,600$ \\
$0,601-0,800$ \\
$0,801-0,999$ \\
1,000
\end{tabular}
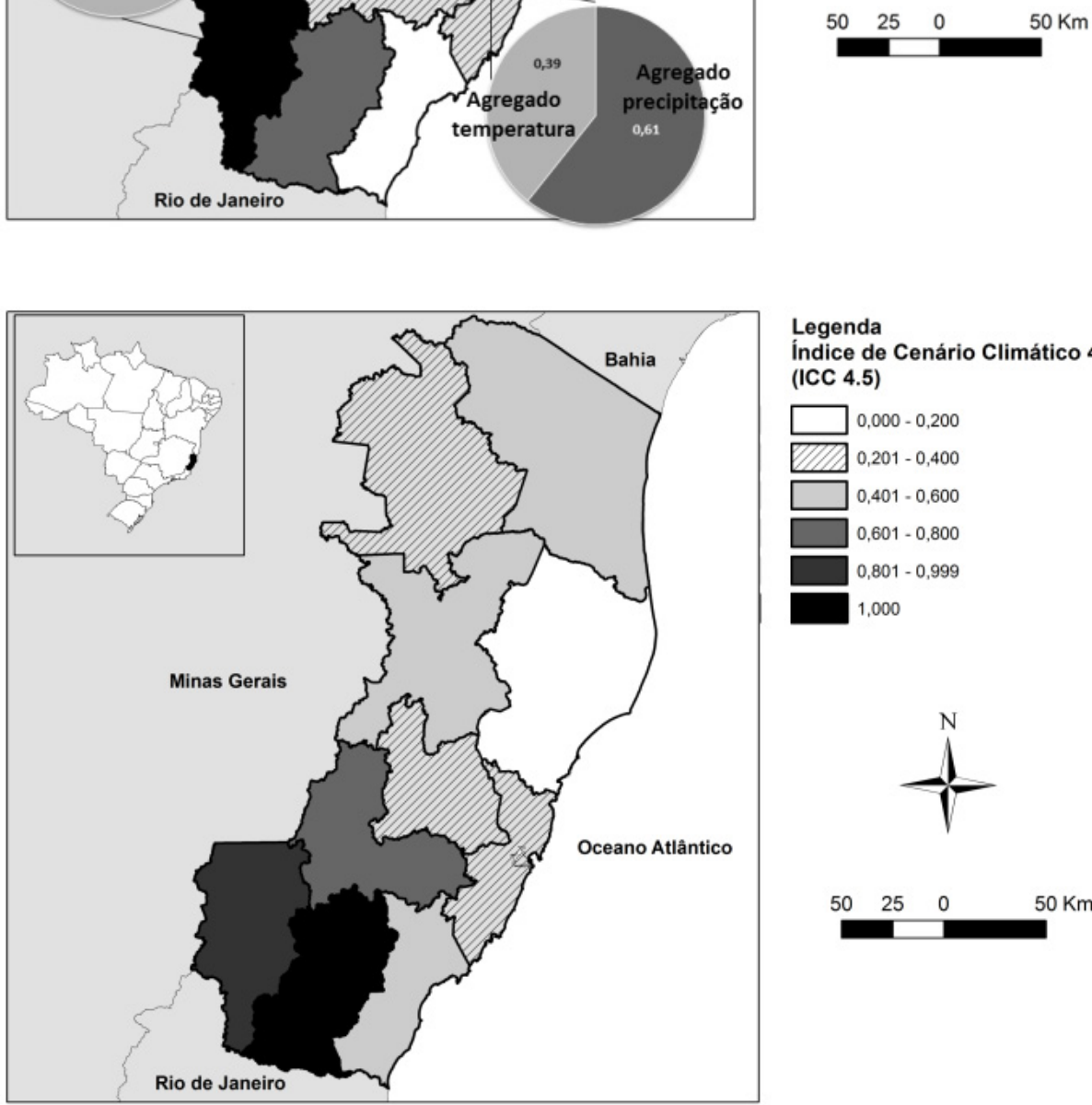

Legenda

Índice de Cenário Climático 4.5 (ICC 4.5)

\begin{tabular}{l}
\hline 0 $0,000-0,200$ \\
$0,201-0,400$ \\
$0,401-0,600$ \\
$0,601-0,800$ \\
$0,801-0,999$ \\
1,000
\end{tabular}

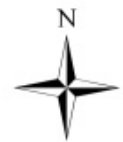

$\begin{array}{lll}50 & 25 & 0\end{array}$

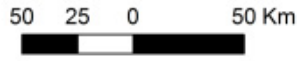




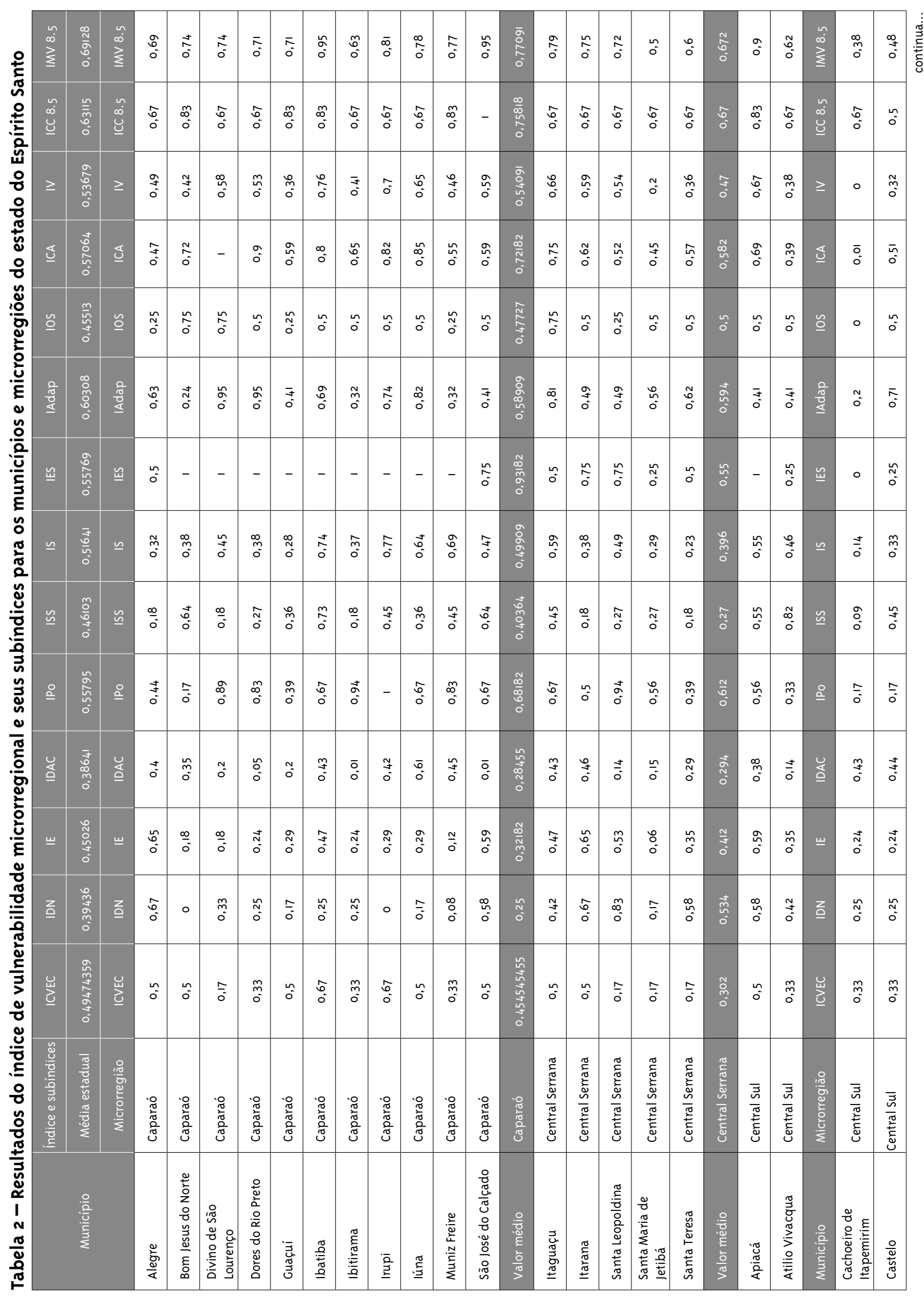




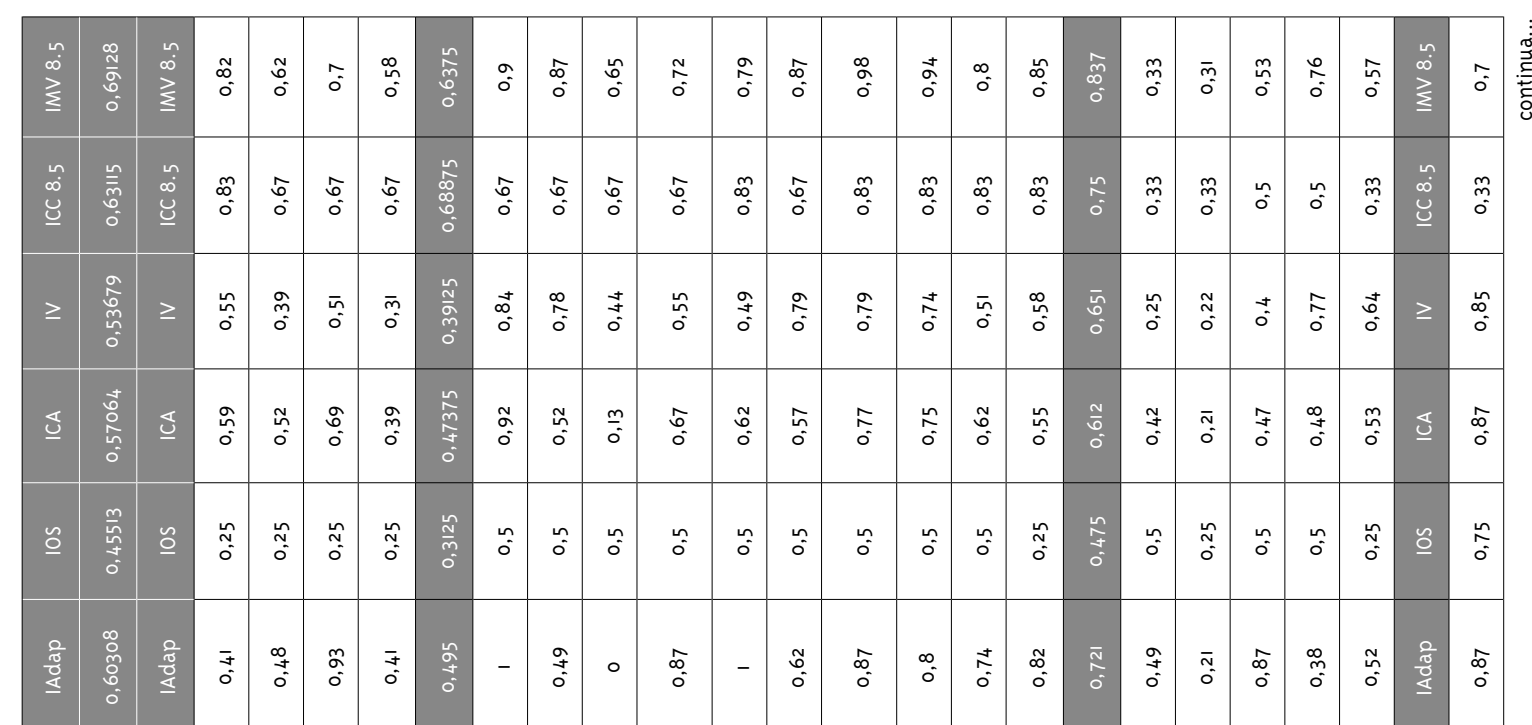

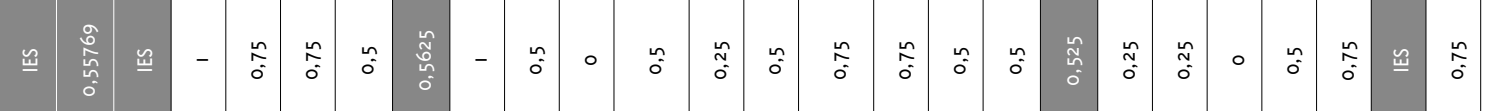

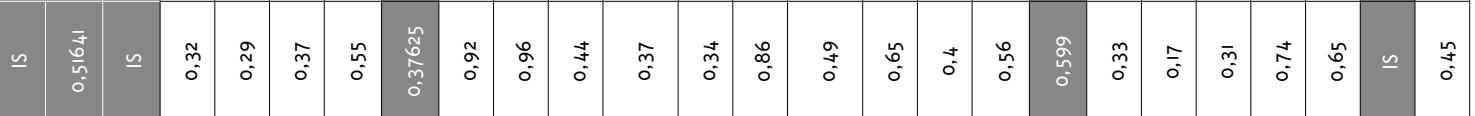

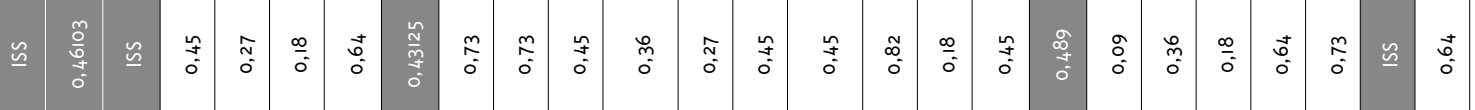

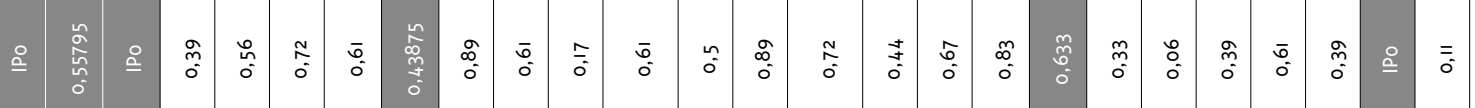

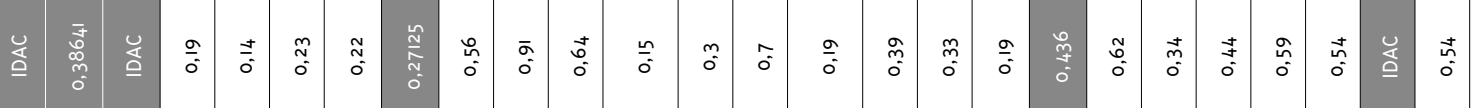

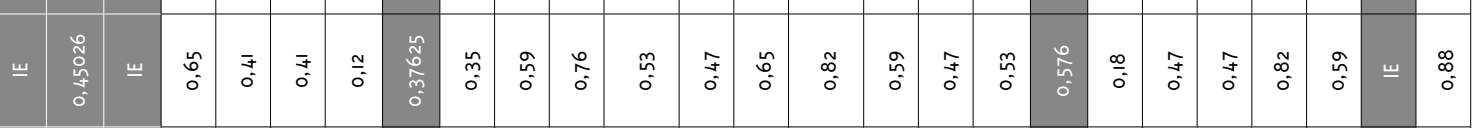

\begin{tabular}{|c|c|c|c|c|c|c|c|c|c|c|c|c|c|c|c|c|c|c|c|c|c|c|}
\hline 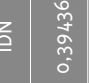 & 兰 & $\begin{array}{l}\hat{0} \\
0 \\
0\end{array}$ & 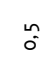 & 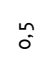 & $\begin{array}{l}\stackrel{\sim}{\approx} \\
\sigma_{0}^{\prime}\end{array}$ & $\frac{\pi}{7}$ & $\begin{array}{l}\infty \\
0 \\
0 \\
0\end{array}$ & $\begin{array}{l}7 \\
0 \\
0\end{array}$ & $\begin{array}{c}\infty \\
\infty \\
0 \\
0\end{array}$ & $\stackrel{n+2}{0}$ & $\begin{array}{l}7 \\
0 \\
0\end{array}$ & $\hat{o}_{0}^{n}$ & $\begin{array}{l}\stackrel{n}{0} \\
\hat{0}\end{array}$ & $\begin{array}{c}\substack{0 \\
0 \\
0} \\
0\end{array}$ & $\begin{array}{l}\tilde{N} \\
\tilde{O}\end{array}$ & $\begin{array}{c}m \\
m \\
0\end{array}$ & $\begin{array}{l}\circ \\
\stackrel{0}{0} \\
0 \\
0\end{array}$ & $\begin{array}{l}n \\
0 \\
0\end{array}$ & $\stackrel{\tilde{N}}{\tilde{N}}$ & $\begin{array}{l}7 \\
0 \\
0\end{array}$ & $\begin{array}{l}7 \\
0 \\
0\end{array}$ & $\begin{array}{l}\infty \\
: \\
0\end{array}$ \\
\hline
\end{tabular}

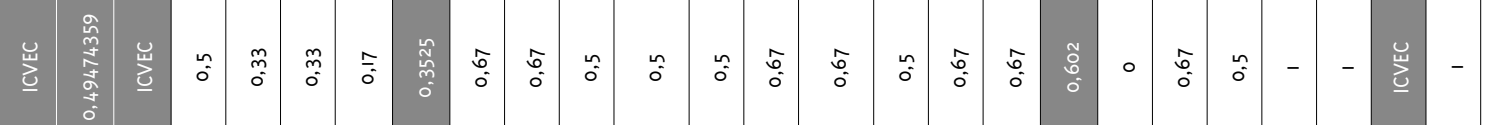

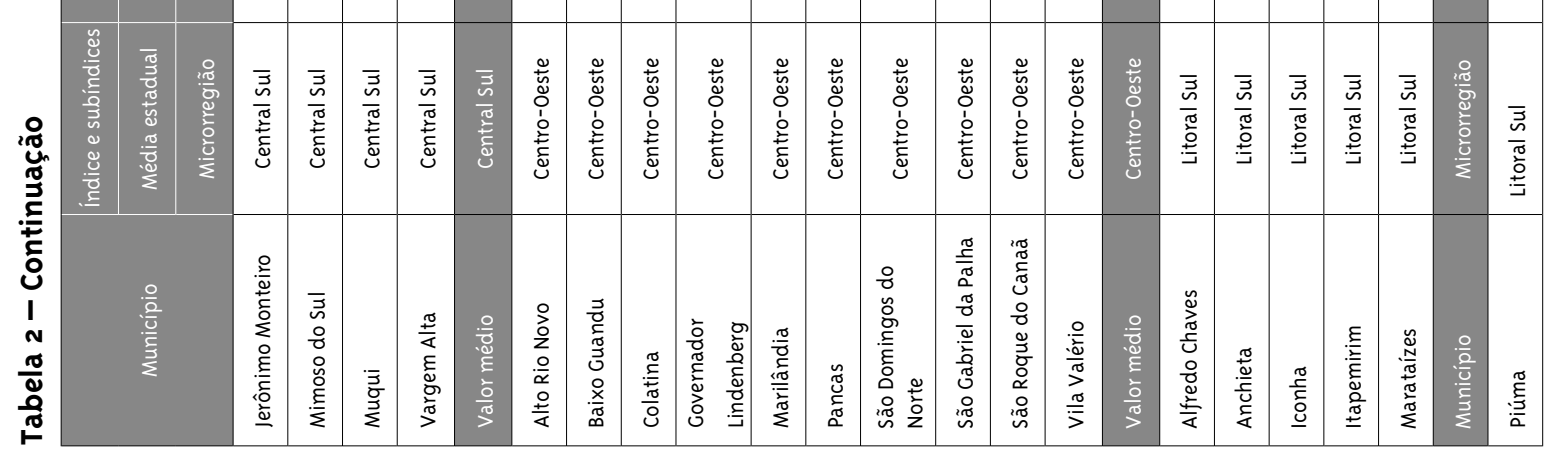




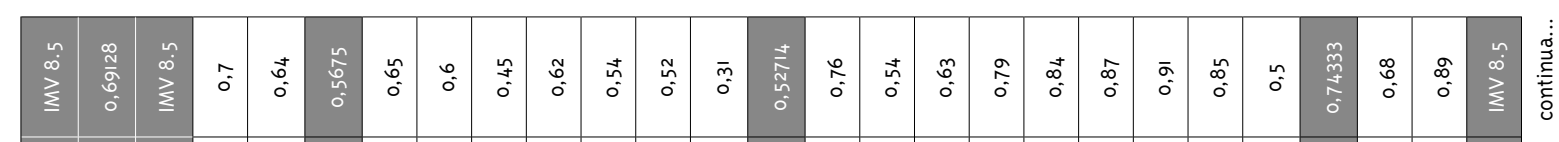

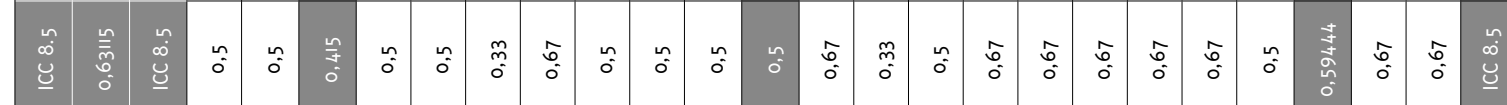

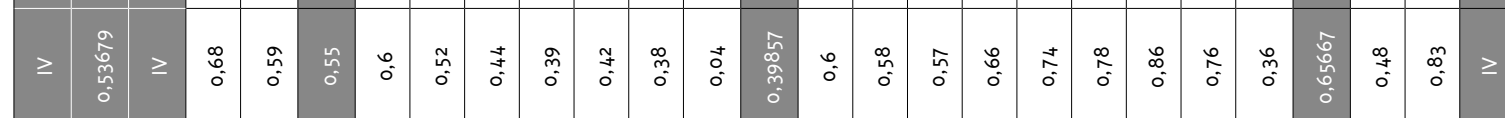

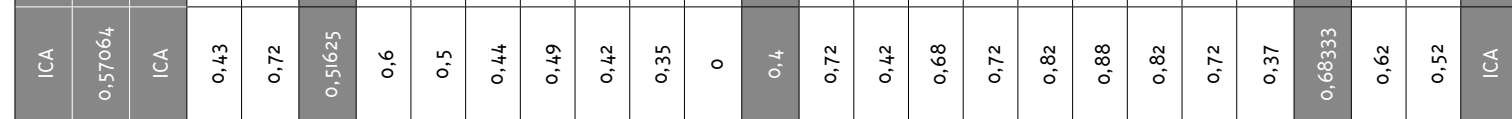

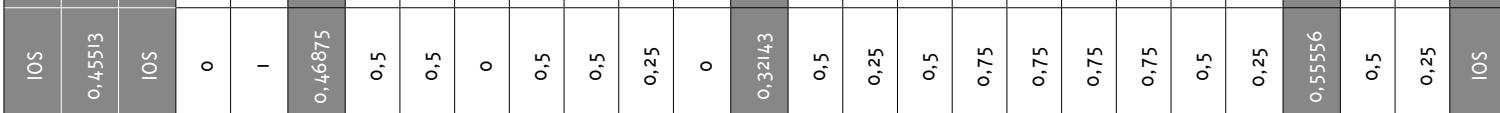

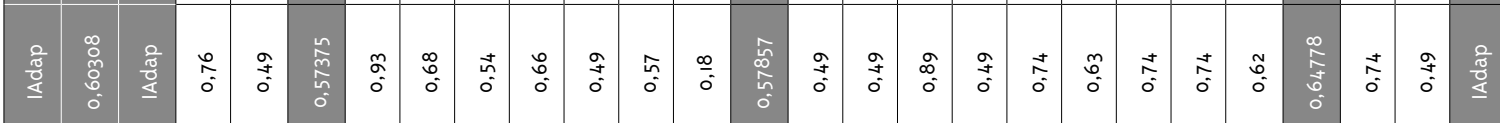

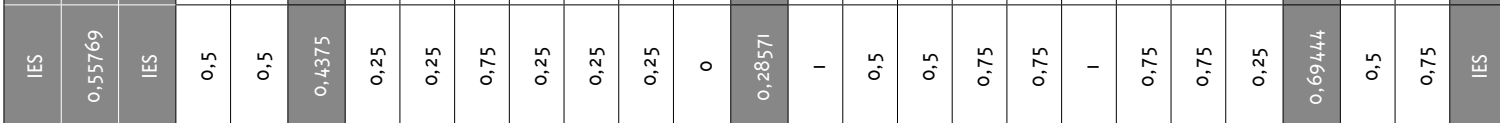

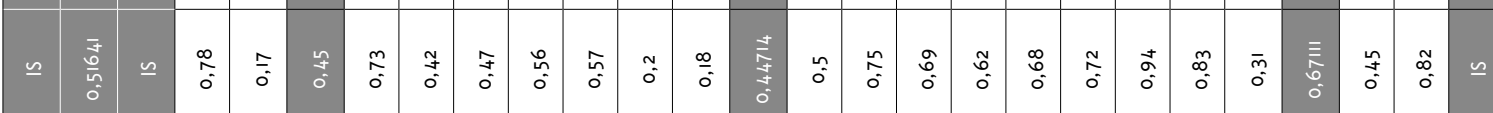

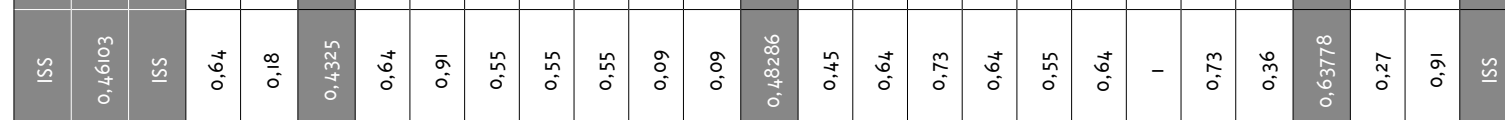

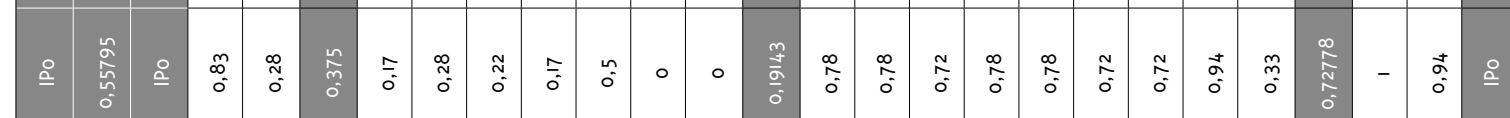

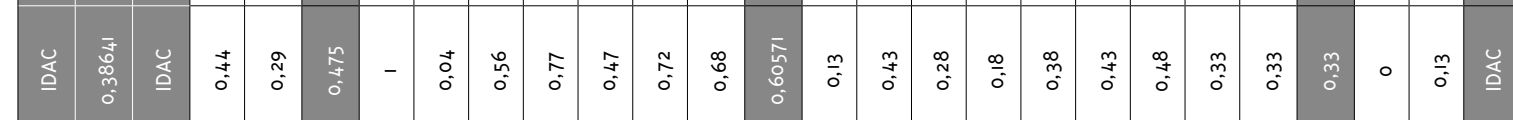

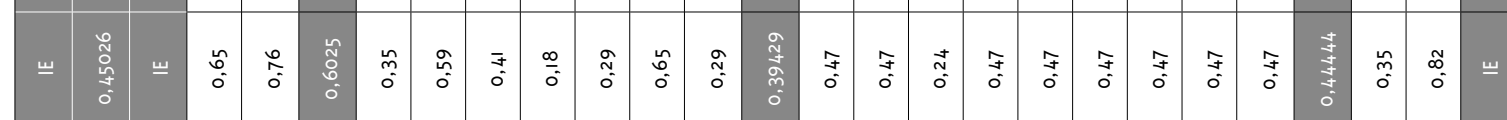

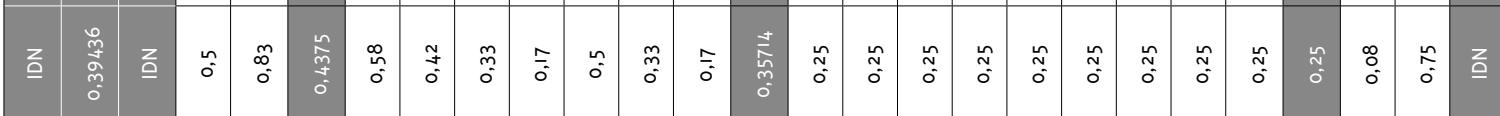

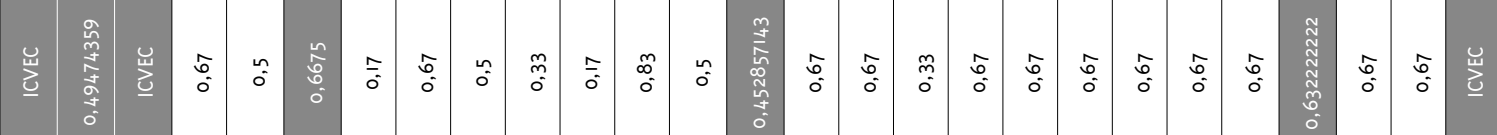

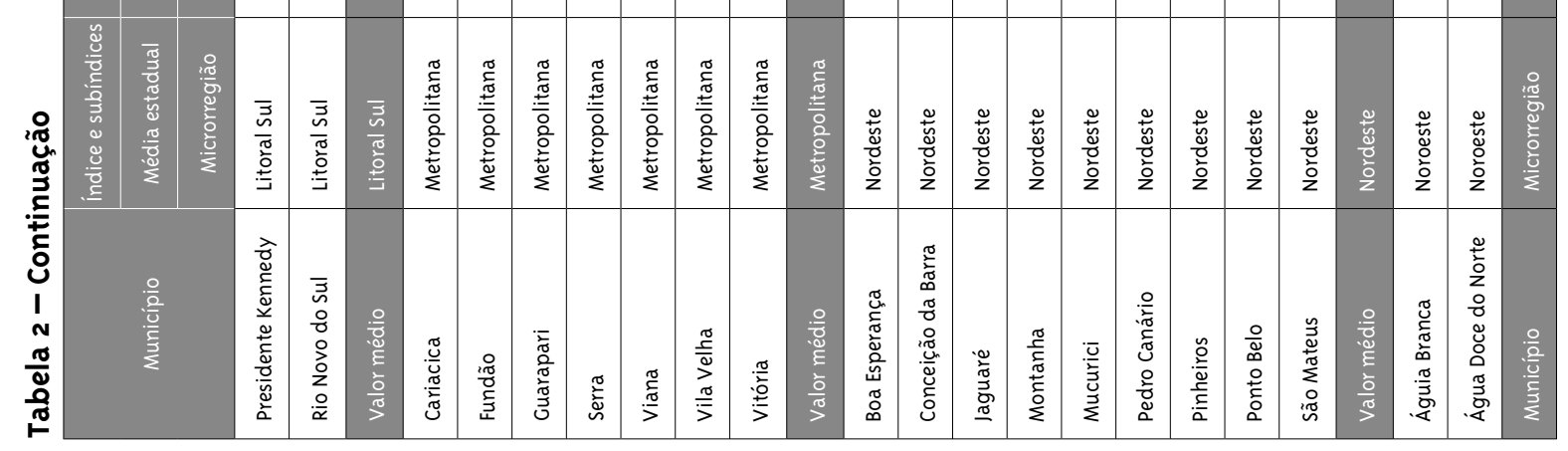




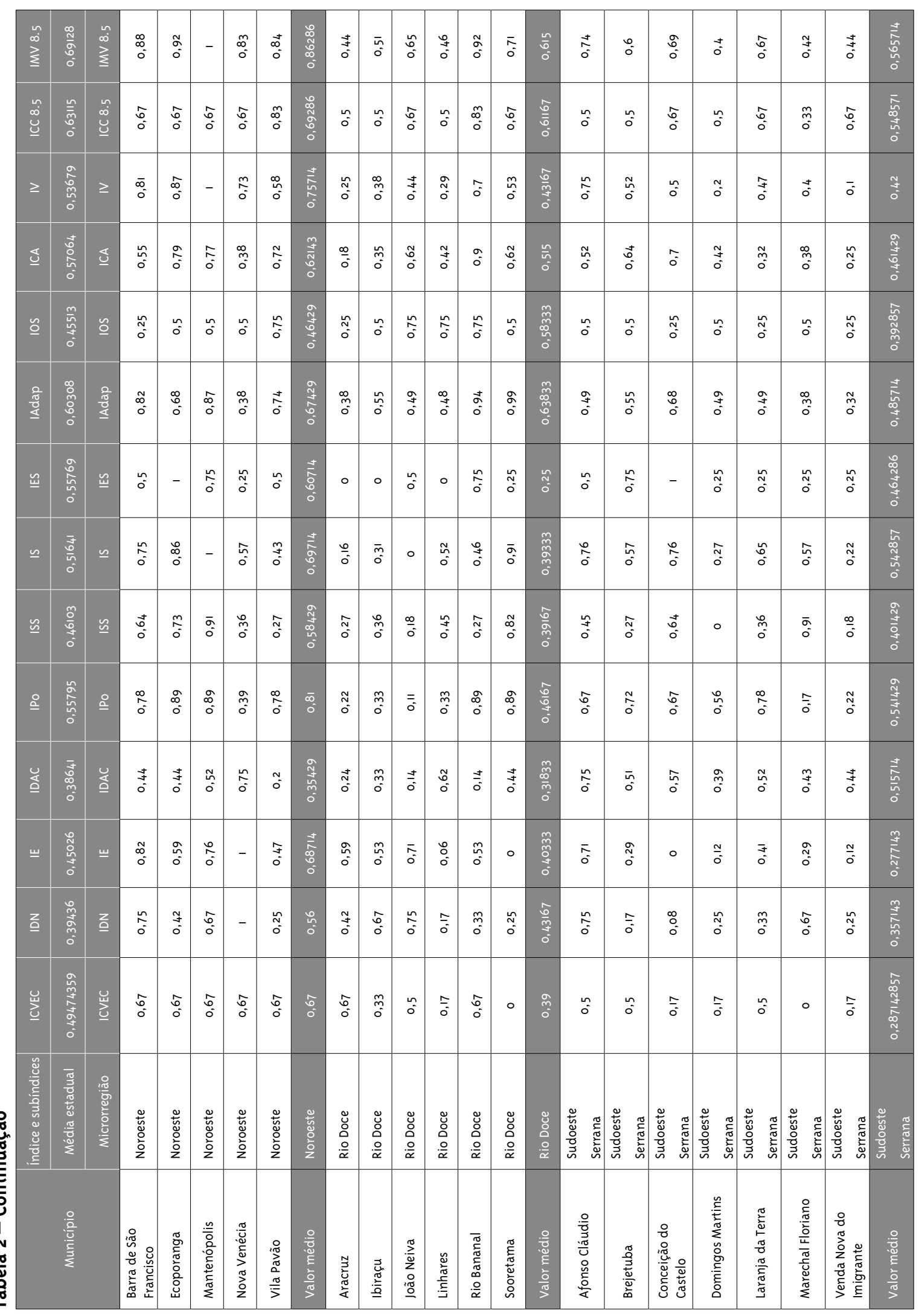


As análises do IVM 4.5 e IVM 8.5 revelaram padrões semelhantes de vulnerabilidade, sendo esta, em geral, maior ao Norte e ao Sul do estado, na divisa com o MG; assim, optou-se por descrever os resultados do IVM 8.5, por serem provenientes de um cenário climático mais pessimista.

Ao se avaliar conjuntamente a vulnerabilidade (IV) e as projeções do clima (ICC 8.5) no IVM 8.5, o maior valor é verificado na microrregião Noroeste (1,oo - alta vulnerabilidade) (Figura 5).

$\mathrm{Na}$ microrregião em questão, o IV também apresentou valor representativo de alta vulnerabilidade $(1,00)$ (Tabela 1$)$. 0 mesmo padrão não foi percebido na análise do ICC 8.5 para essa microrregião, uma vez que o maior valor desse índice ocorreu no Caparaó, localizada ao Sul do estado.

Figura 5 - Índice de vulnerabilidade microrregional 8.5 (IVM 8.5) para o estado do Espírito Santo

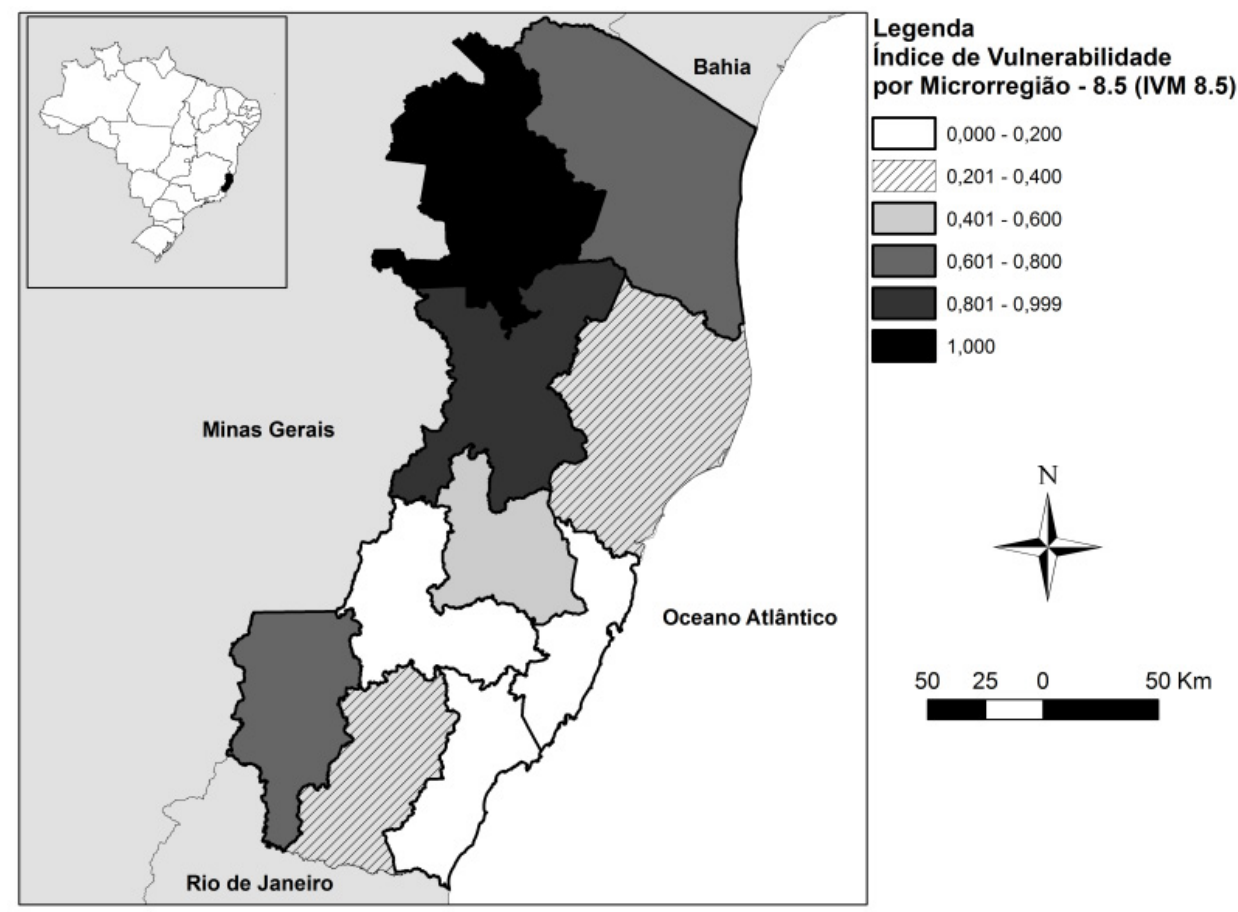

\section{Discussão}

A distribuição espacial da vulnerabilidade (IV) e da mesma acrescida da variável climática (IVM 8.5) apontaram que a microrregião Noroeste foi a que apresentou os maiores valores - alta vulnerabilidade. Para os subíndices do IV, a exposição e a sensibilidade foram determinantes. Esse perfil pode ser explicado pelo histórico de exploração ambiental e migração observada nessa região durante o processo de colonização do estado.

Verifica-se que áreas ao Norte foram originalmente ocupadas por populações socialmente excluídas (isto é, escravos, mestiços e índios); além de terem sido extremamente desmatadas em busca do ganho econômico trazido pela exploração de madeira e pela cultura de eucalipto (Mendes, 2013). Assim, os elevados IE e IS encontrados na microrregião Noroeste correspondem a uma matriz de problemas estaduais com origem histórica refletidos em condições vivenciadas atualmente. Percebe-se que a elevada exposição atual a alterações do clima, traduzida pelo alto valor do IE, é ratificada e agravada por caraterísticas como poucas unidades de conservação e grandes áreas de pastagem encontradas no Noroeste. Além disso, 
percebe-se que muitos municípios nessa região são extremamente afetados pela seca (Brasil, 2005; Espírito Santo, 2015).

Ainda na referida microrregião, no que se refere ao IV e seus componentes, o elevado valor do IS leva a refletir sobre questões sociais e econômicas, visto que alguns grupos (idosos, crianças, deficientes, pobres) podem ser afetadas de forma mais intensa pela mudança do clima e apresentam maior dificuldade de se adaptar a novos quadros, como de doenças transmissíveis e alterações de temperatura (Braga; Oliveira; Givisiez, 20o6; Brasil, 2005; Freitas et al., 2014). A estreita relação entre a vulnerabilidade populacional, o menor poder socioeconômico, a ocupação inadequada do solo e a falta de políticas contínuas, principalmente para populações expostas à seca, é evidenciada por Freitas et al. (2014) ao analisar a situação do Brasil perante impactos dos desastres naturais na saúde das populações. Os autores demonstram que processos sociais resultantes de precárias condições de vida e proteção social contribuem para que determinados grupos sejam mais vulneráveis (por exemplo, pobres, mulheres, crianças e idosos).

Informações do Atlas de Desenvolvimento Humano do Brasil ${ }^{2}$ corroboram os resultados referentes à pobreza verificados por este trabalho nas microrregiões Noroeste e Nordeste - esta última figurou entre as de maior IV. $O$ índice Gini dos municípios integrantes dessas microrregiões demonstra alta concentração de renda nesses locais quando comparados a outras microrregiões do estado, como a Sudoeste Serrana e a Central Serrana. Além disso, dados do último censo indicavam: (1) alto percentual de população em empregos informais, ou seja, sem carteira assinada; e (2) elevado percentual de pessoas em domicílios em que ninguém tem o ensino fundamental completo. ${ }^{3}$

Em relação aos resultados para o ICC 8.5, observou-se que grande parte do estado possui elevada exposição às alterações do clima e que, apesar de o maior valor de ICC 8.5 ser verificado na microrregião Caparaó, todo o estado poderá vivenciar alterações de temperatura importantes, enquanto a região Norte ganha destaque devido às diminuições de precipitação.

As questões sociais e econômicas podem fazer com que o impacto da mudança do clima se processe de forma mais intensa em áreas ao norte do ES, uma vez que as alterações climáticas projetadas podem funcionar como agravante dessas condições. Essa região já apresenta características ambientais atuais delicadas (por exemplo, o baixo percentual de cobertura vegetal nativa), mas, além disso, há baixa precipitação média anual quando comparada às demais regiões do estado, bem como elevado número de registros de estiagem e seca no período de 1990 a 2012 (Ceped, 2013).

Verificou-se que as áreas ao norte, incluindo a microrregião Noroeste, apesar de não apresentarem o maior valor de ICC 8.5, poderão mostrar importante aumento de dias secos consecutivos, diminuição da precipitação média anual e elevação de temperatura média nos próximos 20 anos. Estas características, aliadas ao cenário de degradação ambiental, contribuem para o processo de desertificação ao qual alguns municípios localizados ao norte do ES, principalmente no Noroeste, já estão susceptíveis.

A desertificação é caracterizada pela destruição dos recursos naturais por ação humana e/ou pela variabilidade do clima e, embora lenta, pode ser extremamente prejudicial à sobrevivência das pessoas em localidades afetadas. As áreas susceptíveis a esse processo tendem a apresentar longos períodos de seca intercalados com chuvas concentradas, gerando prejuízos econômicos que afetam de forma mais acentuada populações pobres (Brasil, 2005).

Em 2005 o governo lançou o Programa de Ação Nacional de Combate a Desertificação e Mitigação dos Efeitos da Seca, com o objetivo de combater a desertificação e seus efeitos na população. Dentre as medidas adotadas com base nessa política, destacam-se a diminuição da pobreza e desigualdade e a preservação, recuperação e proteção de recursos naturais por meio de políticas públicas e investimento privado. A maioria de municípios que integram a região abrangida está localizada

2 ATLAS DE DESENVOLVIMENTO HUMANO NO BRASIL. Consulta. [2010]. Disponível em: <https://bit.ly/2LOAtYh>. Acesso em: 7 dez. 2018. 3 ATLAS DE DESENVOLVIMENTO HUMANO NO BRASIL. Consulta. [2010]. Disponível em: 〈https://bit.ly/2LOAtYh>. Acesso em: 7 dez. 2018. 
no Nordeste brasileiro, porém, em virtude das importantes secas vivenciadas em Minas Gerais e no Espírito Santo, municípios desses dois estados também foram incluídos no programa (Brasil, 2005).

Os resultados deste estudo, que evidenciaram características de diminuição de precipitação e aumento de temperatura ao norte do estado, corroboram dados do relatório produzido pelo Instituto Interamericano de Cooperação para a Agricultura (IICA), em 2011, que realizou um diagnóstico das áreas susceptíveis ao processo de desertificação no Espírito Santo. Ele relaciona o processo de desertificação a atividades agrícolas, industriais e de extração mineral e a características como balanço hídrico negativo, clima predominantemente seco e condições sociais presentes no Noroeste do Espírito Santo (IICA, 2011).

Esse quadro evidencia a importância da discussão sobre o acesso à água em situações de seca, evento que tem sido mais frequente, principalmente nas zonas áridas e semiáridas do planeta, devido também às ações antropogênicas que prejudicam a utilização e disponibilização da água para a população (Brasil, 2005). O desastre tecnológico ocorrido em 2015, na cidade de Mariana, em Minas Gerais, é um exemplo de como ações humanas interferem na disponibilidade hídrica. O desastre ocorreu devido ao rompimento de uma barragem de mineração no estado e afetou o abastecimento de água para diversos municípios localizados também no Espírito Santo, principalmente os que se encontravam nas microrregiões Centro-Oeste e Rio Doce, em virtude da contaminação de um importante rio na região, o rio Doce. Mesmo após dois anos do desastre, análises realizadas pela Fundação Sos Mata Atlântica apontam que em muitos pontos do curso do rio as águas ainda permanecem impróprias para consumo, irrigação e pesca (Qualidade..., 2017).

Os impactos da seca podem ser percebidos, por exemplo, na agricultura. No ES, a cultura de café conilon, uma das principais plantações do estado, enfrentou problemas devido à seca no ano de 2016, sendo a área plantada em 2017 ainda mais reduzida quando comprada a do ano anterior (Espírito Santo, 2017). No longo prazo, na agricultura e pecuária, pode haver impacto principalmente para os pequenos produtores e a agricultura familiar, bem como a instalação gradativa de quadros de insegurança alimentar, desnutrição e impactos no crescimento infantil (Filho et al., 2014). Ressalta se ainda que eventos climáticos extremos, como a seca, estimulam movimentos migratórios e interferem em toda a dinâmica de funcionamento das localidades, inclusive no panorama de doenças endêmicas e epidêmicas (Opas, 2009).

Nesse contexto o setor da saúde assume prerrogativas importantes, não apenas pelos impactos diretos da alteração do clima (como as secas, por exemplo), mas também pelos indiretos, como é o caso das doenças infecciosas. No Brasil, muitas doenças, como dengue, leptospirose e leishmaniose, transmitidas por vetores e/ou veiculação hídrica, são sensíveis à alteração do clima e podem ser agravadas tanto por eventos relacionados ao excesso de água (enchentes e alagamentos) quanto por sua escassez, uma vez que, nessas situações, a qualidade da água utilizada pela população pode ser comprometida (Confalonieri, 2003; Freitas et al., 2014).

A ocorrência de doenças e eventos climáticos tem sido descrita por muitos autores que buscam evidenciar a relação existente entre esses elementos (Freire; Bonfim; Natenzon, 2014; Stanke et al., 2013). Dutra et al. (2015), ao avaliarem a ocorrência de casos de leptospirose em Minas Gerais, verificaram o componente climático possivelmente relacionado à retração e expansão da doença. Londe et al. (2015), por sua vez, ao examinarem a ocorrência de leptospirose em Blumenau e Itajaí, perceberam um aumento de quase quatro vezes no número de casos da doença após inundações em novembro de 2008.

As secas, por se tratarem de um fenômeno lento, muitas vezes são responsáveis por impactos indiretos na saúde ao comprometerem condições de sobrevivência, levando ao adoecimento, ao sofrimento e à morte (Stanke et al., 2013). Esse fenômeno tem sido relacionado, inclusive, a doenças mentais, conforme evidenciado por Sartore, Brian e Stain (2007) ao relacionarem a seca ao aumento de estresse e incertezas, que podem levar a quadros de isolamento social, depressão e ansiedade.

As condições subjacentes de cunho social, ambiental, político e de saúde utilizadas para definir o perfil de vulnerabilidade avaliado pelo IV podem 
apresentar, em muitas situações, relevância superior às futuras alterações do clima, já que a mudança deste ocorre em intensidades distintas a depender da localidade e pode ser agravada por condições socioambientais desfavoráveis.

A análise dos resultados para o IVM 8.5 demonstra que na microrregião Noroeste, a de maior IVM médio do estado, de forma geral, o IV apresentou maior relevância quando comparado ao ICC 8.5. Ao se repetir essa análise para os municípios de maior valor de IVM 8.5, percebe-se que em Mantenópolis, a exemplo do que acontece no Noroeste, o valor de IV foi mais importante para o resultado final, enquanto em São Domingos do Norte, São José do Calçado e Ibatiba observou-se que a exposição futura (ICC 8.5) foi mais relevante para os resultados verificados. Relação semelhante foi observada por Menezes et al. (2018) para o estado do Amazonas, em que os hotspots de vulnerabilidade verificados apresentavam contribuições distintas da alteração climática futura e das condições socioambientais atuais para determinar o perfil de vulnerabilidade dos municípios mais críticos.

Desse modo, medidas de adaptação são tão importantes quanto de mitigação, já que ações como direcionamento de políticas públicas a hotspots de vulnerabilidade e estímulos para o estabelecimento de um capital social organizado e atuante podem ser extremamente úteis para o aumento da resiliência e diminuição de impactos das alterações do clima sobre a população (Braga; Oliveira; Givisiez, 2006).

Acredita-se que os índices que abordam a vulnerabilidade socioambiental são úteis para conduzir recomendações políticas remetidas à mitigação e prevenção (Demirkesen; Evrendilek, 2017). Medidas preventivas são economicamente mais viáveis - porém, decorrem de conhecimento aprofundado da realidade e planejamento eficaz, que envolva tanto governantes como o setor privado (Marengo et al., 2009). Dessa forma, o mapeamento das vulnerabilidades observadas neste trabalho é um passo importante para identificar os pontos críticos e facilitar a interpretação desse fenômeno complexo pelos tomadores de decisão, podendo contribuir, no médio prazo, para a proposição de políticas públicas mais efetivas no contexto da mudança do clima.

\section{Conclusão}

A utilização de indicadores compostos permite a união de uma série de informações que, representadas por um único número, propiciam a identificação de hotspots de vulnerabilidade no ES. Acredita-se que este trabalho, a partir das informações geradas, possa subsidiar ações relacionadas à adaptação, contribuindo para a diminuição da vulnerabilidade à mudança do clima das microrregiões do estado, assim como colaborar para o aperfeiçoamento e a disseminação dos estudos do tema.

\section{Referências}

ADGER, W. N. Vulnerability. Global

Environmental Change, Amsterdam, v. 16. p. 268281, 2006.

BARATA, M. et al. Mapa de vulnerabilidade da população do estado do Rio de Janeiro aos impactos das mudanças climáticas nas áreas social, saúde e ambiente: Relatório Executivo $n^{0}$ 4. Rio de Janeiro: Fiocruz, 2011. Disponível em: <https://bit.ly/2QnOL2w>. Acesso em: 3 abr. 2017.

BRAGA, T.; OLIVEIRA, E.; GIVISIEZ, G. Avaliação de metodologias de mensuração de risco e vulnerabilidade social a desastres naturais associados à mudança climática. São Paulo em Perspectiva, São Paulo, v. 20, n. 1, p. 81-95, 2006.

BRASIL. Ministério do Meio Ambiente. Programa de Ação Nacional de Combate à Desertificação e Mitigação dos Efeitos da Seca. Brasília, DF: Secretaria de Recursos Hídricos, 2005. Disponível em: <https://bit.ly/2MkcH5o>. Acesso em: 11 jan. 2018.

BRASIL. Plano Nacional de Adaptação à Mudança do Clima: estratégias setoriais e temáticas. Brasília, DF: Ministério do Meio Ambiente, 2016. v. 2. Disponível em: <https://bit.ly/2LGY7Jm>. Acesso em: 29 set. 2016.

CEPED - CENTRO UNIVERSITÁRIO DE ESTUDOS E PESQUISAS SOBRE DESASTRES. Atlas brasileiro de desastres naturais: 1991 a 2012: volume Espírito Santo. 2. ed. rev. ampl. Florianópolis: Ceped UFSC, 2013. 
CHOU, S. C. et al. Assessment of climate change over South America under RCP 4.5 and 8.5 downscaling scenarios. American Journal of Climate Change, Wuhan, v. 3, n. 5, p. 512-527, 2014. CONFALONIERI, U. E. C. Variabilidade climática, vulnerabilidade social e saúde no Brasil. Terra Livre, São Paulo, ano 19, v. 1, n. 20, p. 193-204, 2003.

CONFALONIERI, U. E. C.; BARATA, M. M. L.; MARINHO, D. P. M. Vulnerabilidade climática no Brasil. In: CHANG, M. et al (Ed.). Metodologias de estudos de vulnerabilidade à mudança do clima. Rio de Janeiro: Interciência, 2015. v. 5. p. 25-38. (Coleção Mudanças Globais).

CONFALONIERI, U. E. C.; QUINTÃO, A. F.; BRITO, I. F. Vulnerabilidade municipal às mudanças climáticas: o caso de Minas Gerais e da Bacia do Alto Rio Paraguai - Brasil. In: CONFALONIERI, U. E. C.; QUINTÃO, A. F. (Ed.). Vulnerabilidade à mudança climática na América Latina: instrumentos regionais para a adaptação no setor saúde. Belo Horizonte: Centro de Pesquisas René Rachou, 2016. p. 45-79.

CUTTER, S. L.; FINCH, C. Temporal and spatial changes in social vulnerability to natural hazards. Proceedings of the National Academy of Sciences of the United States of America, Washington, DC, v. 105, n. 7, p. 2301-2306, 2008.

DE SHERBININ, A. et al. Preparing for resettlement associated with climate change. Science, Washington, DC, v. 334, n. 6.055, p. 456457, 2011.

DONI, M. V. Análise de cluster: métodos hierárquicos e de particionamento. 2004. Monografia (Bacharelado em Sistemas de Informação) - Universidade Presbiteriana Mackenzie, São Paulo, 2004. Disponível em: <https://bit.ly/2BW07oB>. Acesso em: 9 jan. 2018.

DUTRA, F. L. S. et al. A influência da variabilidade da precipitação no padrão de distribuição dos casos de leptospirose em Minas Gerais, no período de 1998-2012. Hygeia, Uberlândia, v. 11, n. 20, p. 106-126, 2015 .
DEMIRKESEN, A. C.; EVRENDILEK, F.

Compositing climate change vulnerability of a Mediterranean region using spatiotemporally dynamic proxies for ecological and socioeconomic impacts and stabilities. Environmental Monitoring and Assessment, Dordrecht, v. 189, n. 1, p. 29, 2017.

ESPÍRITO SANTO. Lei n ${ }^{0}$ 9.768, de 20 de dezembro de 2011. Dispõe sobre a definição das microrregiões e macrorregiões de planejamento no estado do Espírito Santo. Diário Oficial do Estado, Vitória, 28 dez. 2011. Disponível em: <https://bit.ly/2QgXad9>. Acesso em: 18 ago. 2015. ESPÍRITO SANTO. Unidades de conservação. Instituto Estadual do Meio Ambiente e Recursos Hídricos, Cariacica, 2015. Disponível em: <https:// bit.ly/2F3auvL >. Acesso em: 4 jan. 2018.

ESPÍRITO SANTO. Secretaria de Economia e Planejamento. Panorama econômico do Espírito Santo: $3^{\circ}$ trimestre de 2017. Vitória: Instituto Jones dos Santos Neves, 2017. Disponível em: <https://bit.ly/2AYıfbp>. Acesso em: 13 jan. 2018.

FILHO, S. R. et al. Impactos regionais, adaptação e vulnerabilidade ao clima e suas implicações para a sustentabilidade regional no Brasil. In: ASSAD, E. D.; MAGALHÃES, A. R. (Ed.). Impactos, vulnerabilidade e adaptação. 2. ed. Rio de Janeiro: Instituto Alberto Luiz Coimbra de Pós-Graduação e Pesquisa de Engenharia, 2014. p. 335-419.

FREIRE, N. C. F.; BONFIM, C. V.; NATENZON, C. E. Vulnerabilidade socioambiental, inundações e repercussões na saúde em regiões periféricas: o caso de Alagoas, Brasil. Ciência e Saúde Coletiva, Rio de Janeiro, v. 19, n. 9, p. 3755-3762, 2014.

FREITAS, C. M. et al. Desastres naturais e saúde: uma análise da situação do Brasil. Ciência e Saúde Coletiva, Rio de Janeiro, v. 19, n. 9, p. 3645-3656, 2014 .

FÜSSEL, H. M. Adaptation planning for climate change: concepts, assessment approaches, and key lessons. Sustainability Science, New York, v. 2, n. 2, p. 265-275, 2007.

IICA - INSTITUTO INTERAMERICANO DE COOPERAÇÃO PARA AGRICULTURA. PCT 
BRA/IICA/05/oo4 (PAN DESERTIFICAÇÃO): Produto C: Relatório com diagnóstico descritivo das condições atuais das áreas susceptíveis a desertificação do estado do Espírito Santo sob a ótica do eixo temático do PAN-Brasil "ampliação sustentável da capacidade produtiva”, a partir da análise de dados secundários existentes, buscando inclusive a atualização do Panorama de Desertificação no Estado do Espírito Santo. Vitória: Instituto Estadual de Meio Ambiente e Recursos Hídricos do Estado do Espírito Santo, 2011. Disponível em: <https://bit.ly/2SxiCYh>. Acesso em: 3 abr. 2017.

IPCC - INTERGOVERNMENTAL PANEL ON CLIMATE CHANGE. Climate change 2007: impacts, adaptation and vulnerability: technical summary. Cambridge: Cambridge University Press, 2007.

LEE, J. R. et al. Mapping the drivers of climate change vulnerability for Australia's threatened species. PLoS One, San Francisco, v. 10, n. 5, 2015.

LONDE, L. R. et al. Impactos de desastres socioambientais em saúde pública: estudos dos casos dos estados de Santa Catarina em 2008 e Pernambuco em 2010. Revista Brasileira de Estudos de População, Rio de Janeiro, v. 32, n. 3, p. 537-562, 2015.

MARENGO, J. et al. Mudanças climáticas e eventos extremos no Brasil. Rio de Janeiro: Fundação Brasileira para o Desenvolvimento Sustentável, 2009. Disponível em: <www.fbds.org.br./fbds/IMG/ pdf/doc-504.pdf>. Acesso em: 27 abr. 2018.

MENDES, O. Desenvolvimento econômico no estado do Espírito Santo versus territórios quilombolas, sob a ótica pós-colonial. Simbiótica, Vitória, v. 1, n. 3, 2013.

MENEZES, J. A. et al. Mapping human vulnerability to climate change in the Brazilian Amazon: the construction of a municipal vulnerability index. PLoS One, San Francisco, v. 13, n. 2, 2018.

OBERMAIER, M.; ROSA, L. P. Mudança climática e adaptação no Brasil: uma análise crítica. Estudos Avançados, São Paulo, v. 27, n. 78, p. 155-176, 2013.
OPAS - ORGANIZAÇÃO PAN-AMERICANA DA SAÚDE. Mudança climática e saúde: um perfil do Brasil. Brasília, DF, 2009.

QUALIDADE da água na bacia do rio Doce piora dois anos após tragédia em Mariana. SOS Mata Atlântica, São Paulo, 2017. Disponível em: <https://bit.ly/2RObıE8>. Acesso em: 7 dez. 2018.

QUINTÃO, A. F. et al. Social, environmental and health vulnerability to climate change: the case of the municipalities of Minas Gerais, Brazil. Journal of Environmental and Public Health, London, v. 2017, 2017.

ROLIM, C. F. C. Um índice de pobreza humana municipal para o Brasil. Texto para Discussão, Curitiba, n. 17, p. 1-25, 2005.

SANTOS, R. B. Vulnerabilidade socioambiental e de saúde dos municípios do estado do Espírito Santo frente aos impactos das mudanças climáticas. 2016. Dissertação (Mestrado em Saúde Coletiva) - Centro de Pesquisas René Rachou, Belo Horizonte, 2016.

SARTORE, G. M.; BRIAN, K.; STAIN, H. J. Drought and its effect on mental health: how GPs can help. Australian Family Physician, East Melbourne, v. 36, n. 12, p. 990-993, 2007.

SOS MATA ATLÂNTICA; INPE - INSTITUTO NACIONAL DE PESQUISAS ESPACIAIS. Atlas dos remanescentes florestais da Mata Atlântica, período 2015-2016: relatório técnico. São Paulo, 2018. Disponível em: <https://bit.ly/2L5ZVrW>.

Acesso em: 20 out. 2017.

STANKE, C. et al. Health effects of drought: a systematic review of the evidence. PLoS Currents Disasters, San Francisco, v. 5, jun. 2013.

\section{Contribuição dos autores}

Santos, Confalonieri e Margonari conceberam e, com Menezes, delinearam o projeto. Santos, Madureira, Duval e Garcia analisaram e, com Confalonieri e Margonari, interpretaram os dados. Menezes, Confalonieri e Margonari revisaram o manuscrito, redigido por Santos.

Recebido: 14/07/2018

Aprovado: $18 / 10 / 2018$ 